\author{
Sergio Tomé FernándeZ \\ Departamento de Geografía, Universidad de Oviedo
}

\title{
La Gran Vía de Madrid y sus márgenes: patrimonio y desarrollo sostenible
}

\section{RESUMEN}

Un debate fundamental en geografía urbana se refiere al efecto cruzado y la difícil compatibilidad entre las políticas de regeneración urbana y los patrones postfordistas de explotación intensiva, en áreas centrales históricas. Interesan especialmente, por su complejidad y fragilidad, los distritos afectados por la apertura de grandes ejes interiores a finales del siglo XIX y principios del $\mathrm{xx}$, calles principales en pantalla, cuyos bordes actúan de bisagra y entran en contraste con la trama antigua.

\section{RÉSUMÉ}

La Gran Vía de Madrid et ses marges: patrimoine et développement durable.- Il est débattu aujourd'hui, dans la géographie urbaine, le conflit entre les politiques de régénération urbaine et les modèles post-fordistes fondés sur l'exploitation économique intensive, dans les zones centrales historiques. Ils sont très intéressants en raison de leur complexité et fragilité les districts avec des grands axes intérieurs ouverts à la fin du XIX ${ }^{\text {ème }}$ siècle et au début du $\mathrm{Xx}^{\text {ème }}$ siècle, qui sont aujourd'hui des avenues principales dont les marges sont les zones de contact avec le tissu urbain ancien.

\section{INTRODUCCIÓN. LA PERSONALIDAD GEOGRÁFICA DE LA GRAN VÍA}

$E^{\text {n }}$ 2010 se celebró oficialmente el centenario del arranque de las obras de la Gran Vía, esa enorme hendidura (1.316 m de longitud por 35 de anchura máxima) que rasgó el entramado del viejo Madrid, aunque la urbanización del primer tramo no concluiría hasta 1917 (Sanz López, 2011, p. 5). Todavía cabe conmemo-

\footnotetext{
${ }^{1}$ Este trabajo se realizó dentro del proyecto de investigación cso 201347205-P, financiado por el Ministerio de Economía y Competitividad.
}

\section{AbSTRACT}

The Gran Ví in Madrid and its margins: heritage and sustainable development.- A fundamental debate that concerns urban geography is about both the crosswise effect and the hard compatibility between urban regeneration policies and post-Fordism patterns of work related to intensive exploitation in central historical area. It would be especially useful, because of their complexity and fragility, districts which are affected by the opening of large axes at the end of the $19^{\text {th }}$ century and the beginning of the $20^{\text {th }}$ century. These main streets are kind of screen, in contrast to the ancient urban weave.

$$
\text { Palabras Clave/Mots Clé/Keywords }
$$

Geografía urbana, Madrid, sostenibilidad urbana, patrimonio cultural, centro urbano.

Géographie urbaine, Madrid, durabilité urbaine, héritage culturel, centre ville.

Urban geography, Madrid, urban sustainability, cultural heritage, city center.

rar el nacimiento de lo que será el escenario fundamental de la representación social urbana, aportando una breve investigación sistemática sobre sus dinámicas recientes (edificatorias, urbanísticas, económicas, poblacionales y de clase), según el método de la geografía y desde una óptica de rehabilitación urbana. Precisamente por razones de método resulta forzoso incluir sus márgenes, es decir las zonas de contacto y franjas laterales más afectadas por la sobreimposición del nuevo eje, que representan una porción sustantiva del centro histórico, extremadamente diversa, compleja y sensible. Observados conjuntamente, la Gran Vía y su entorno componen un 


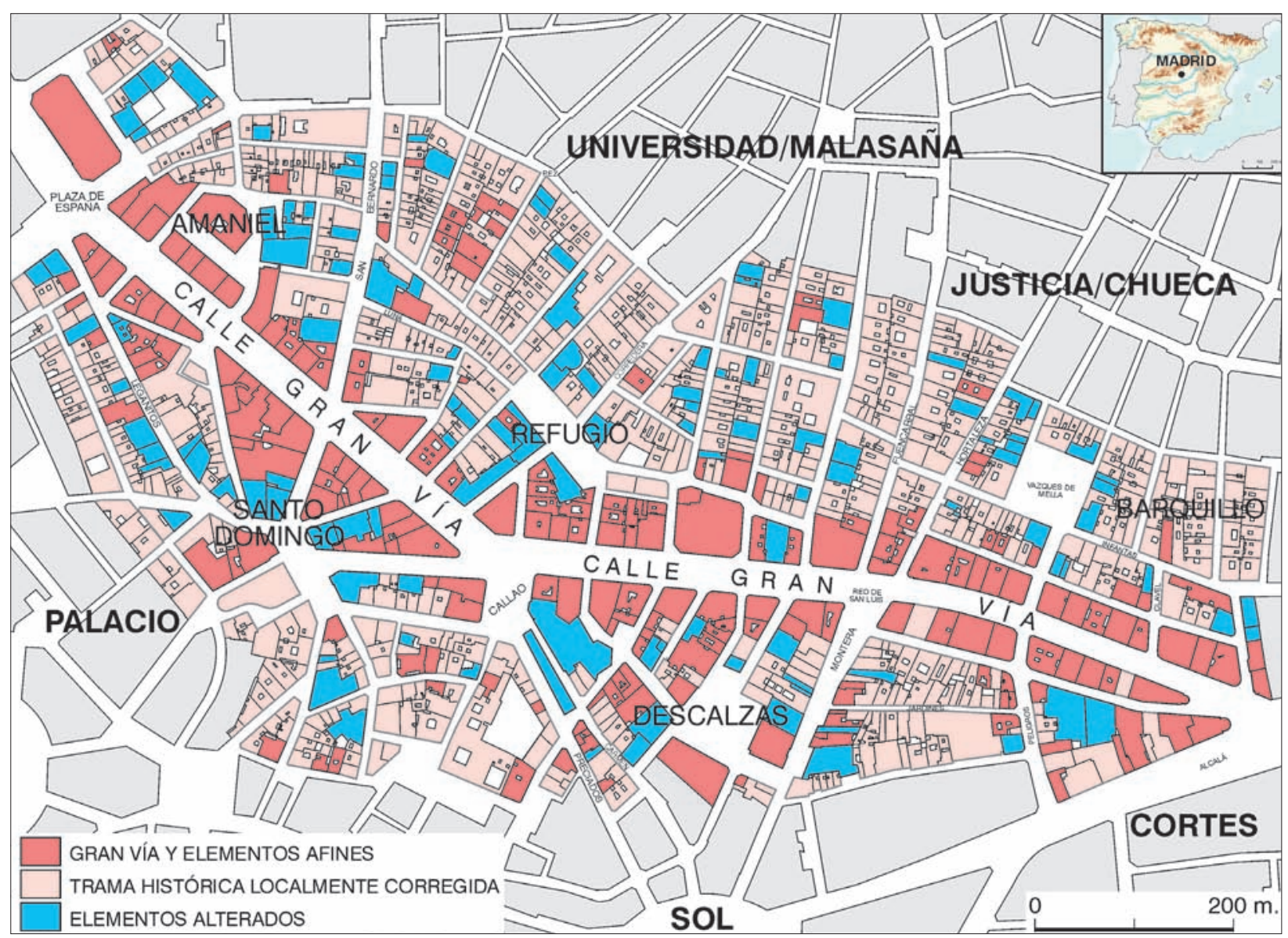

FIG. 1. Gran Vía y sus márgenes, según los límites establecidos en el trabajo.

organismo de gran interés en términos de sedimentación morfológica, rico en estructuras heredadas, edificación civil decimonónica y monumentos modernos, donde se entrecruzan procesos propios de la ciudad antigua (deterioro, inmigración, ocio juvenil, gentrificación, dualidad) y del centro metropolitano (tensiones especulativas, sobre explotación, criba funcional, diferenciación), dando como resultado una realidad muy parcelada.

El área de estudio, delimitada con idea de recoger toda la gama de contrastes y la variedad de interacciones, suma cien manzanas de casas (98 calles completas o tramos) dispuestas en figura disimétrica por el mayor peso de la parte norte (Malasaña, Chueca) frente a la orla meridional (desde Alcalá a Leganitos), donde enseguida se deja sentir el influjo de la Puerta del Sol (Fig. 1). El trabajo sobre el terreno y la consulta de materiales de planeamiento se completaron con el análisis de los datos significativos (licencias de obras, padrones y censos de población, unidades de actividad económica), ajustables a esa escala, procedentes en parte del GIs municipal. La recopilación bibliográfica, complicada por el elevado número de aportaciones previas casi siempre sectoriales o no geográficas, permitió plantear una nueva mirada de conjunto a los procesos actuales dando preferencia a las cuestiones más descubiertas.

Los objetivos urbanísticos, de tipo inmobiliario o concerniente a las actividades terciarias, hacen de la Gran Vía un bulevar haussmaniano fuera de tiempo, concepto exteriorizado de algún modo en la imagen del primer trecho (Hidalgo, Ramos y Revilla, 1996, p. 9; Alaminos López, 2009, p. 59). La parte restante termina de modelar su personalidad geográfica, muy determinada por el lento desarrollo de la operación, su carácter de realización un tanto aislada y la peculiar inserción en el plano. El tiempo transcurrido desde el primer edificio (1911) hasta el último (1952) posibilitará que Estados Unidos se imponga como referencia básica para el cosmopolitismo arquitectónico, pero el paso progresivo hacia una 
fisonomía de tipo americano, con alturas de once o más plantas y hasta treinta en la torre de Madrid que cierra su perspectiva visual, suscita división de opiniones sobre la idoneidad del resultado, especialmente la caída hacia la plaza de España (Corral, 1980, p. 1315). Su parte media se ensambla con el tejido reformado a mediados del siglo XIX en torno a Sol (Montera, Preciados) y los viales vertebradores del macizo urbano (Fuencarral, Hortaleza), realineados, pero sólo recibe una bocacalle con cierta amplitud, de ahí su nombre Ancha de San Bernardo (Quirós Linares, 1983, p. 86). La Gran Vía tiene entonces algo de canal o desfiladero, recoge mucho tránsito, pero no puede derivarlo o redistribuirlo de forma suficiente hacia zonas contiguas, por lo que quizá habría sido más eficaz con una paralela septentrional, la frustrada Gran Vía Diagonal de Malasaña, proyecto de posguerra cuestionado por su efecto bulldozer (De la Cruz, 2010, s. p.). El alzado de la cornisa edificada y la ausencia de facilidades para descargar actividad hacia aquellas partes más contradictorias con la avenida favorecieron desde el origen una densa estratificación multifuncional. Los espectáculos del Broadway madrileño guardaron tradicionalmente un equilibrio dinámico con las viviendas, hoteles, cafés y más tarde cafeterías, el comercio de calidad, los bancos, despachos de profesionales y oficinas (Guerra Garrido, 2002, p. 23). Sólo en fecha reciente la terciarización global impone un radical afinamiento, pero no siempre resulta sencilla la adaptación de los inmuebles de mayores proporciones, edad relativa o elevado precio, como el edificio España, la torre Montesol en la calle Montera o el Coliseum.

La diferencia de altura respecto al caserío contiguo tampoco significa que la Gran Vía sea propiamente una lámina, pues en sus orillas hay un salpicado de elementos coetáneos, particularmente de la posguerra, debidos en ocasiones a los bombardeos. Su línea quebrada en tres secciones, separadas por los anclajes de Red de San Luis y Callao, condicionó y no poco la relación espacial con el estrato urbano más antiguo. La distribución previa de contenidos favoreció el engarce físico y funcional con el centro tradicional (los radios de la Puerta del Sol) y las vías prestigiosas o más activas (San Bernardo, entorno de Barquillo, horquilla Fuencarral-Hortaleza), en las direcciones donde no hay una discontinuidad topográfica marcada. Al revés, las partes impermeables, menos mejoradas por la reforma liberal, con mayor pendiente o deprimidas, no permitieron resolver tan satisfactoriamente la soldadura, quedando relegadas a una condición de asentamientos populares, o traseras cuando contenían usos de rechazo, sobremanera por detrás del Madrid-París. La heterogeneidad se acentuó al avanzar la centuria

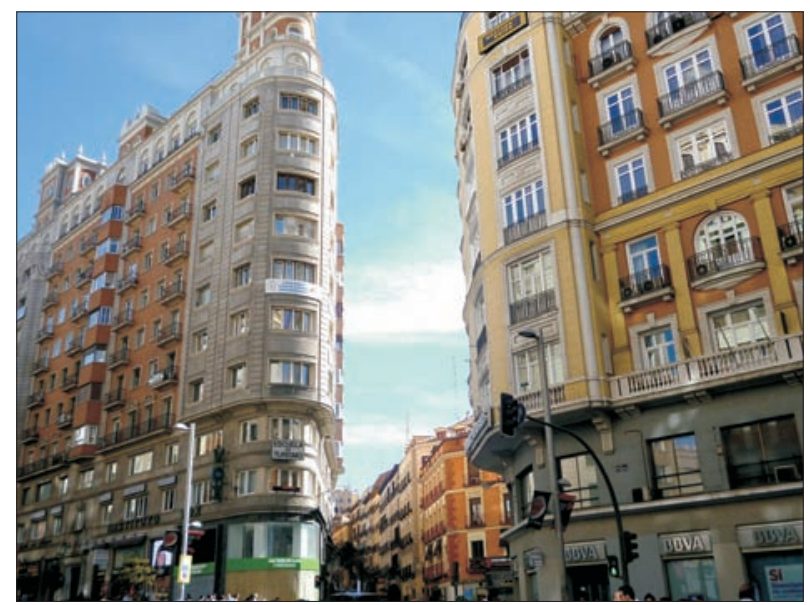

Fig. 2. Salto de escala entre el edificio Los Sótanos (1949) y el tejido histórico de la calle Isabel la Católica.

con el gradual derrame y la desigual presión ejercida sobre los flancos, de manera que la fracción central funcionará como ámbito de desbordamiento donde se producen derribos o se generan disfunciones durante los años setenta, mientras otras calles permanecían más ajenas, mejor conservadas, quizá calcificadas o degradadas por la existencia de bolsas de pobreza, cuando no se comportaban como reverso o negativo con estigma de bajos fondos. Camino al cambio de siglos entraron en juego otras fuerzas que corregirían aquella diversidad interna, marcando distancia entre las calles asimiladas a la Gran Vía, las zonas envejecidas donde la recuperación se abría paso lentamente, encadenada a la diversión juvenil, y los reductos más depauperados, que recibieron trabajadores extranjeros según la lógica del gueto (Plan de Calidad del Paisaje, 2009c, p. 141; Fernández Ramírez, González García y Morán Alonso, 2010, p. 37).

El propósito de estas líneas es valorar los resultados del patrón de intervención flexible aplicado a ese espacio-mosaico en constante adaptación, de fuerte centralidad y profunda carga cultural, complicado de ordenar, incluso si se articulan distintas escalas entre el plan general y las ARI, como evidencia la difícil aplicación del Plan Director del Eje Gran Vía y su Entorno (2009). Cuesta ajustar los parámetros de sostenibilidad con la capitalización intensiva soportada durante los últimos años, que da a la Gran Vía carácter genérico o temático y redefine sus relaciones horizontales. En el contexto de la crisis se acelera la puesta en valor de las márgenes (recuperación urbanística o patrimonial, conquista social), de manera no uniforme sino con desfases y evoluciones locales diferenciadas. Las contradicciones engendradas (precios, 
CuAdro I. Categorías aplicadas en el Catálogo de patrimonio (1997)

\begin{tabular}{|c|c|c|}
\hline Niveles de protección & Grados & Obras admisibles \\
\hline \multirow[t]{2}{*}{ Protección global } & Grado singular & Intervenciones menores \\
\hline & Grado integral & Intervenciones menores \\
\hline \multirow[t]{2}{*}{ Protección de conjunto o estructural } & Grado estructural & Reestructuración parcial, parquin subterráneo \\
\hline & Grado volumétrico & Reestructuración general, vaciado y recrecimiento, parquin subterráneo \\
\hline \multirow[t]{2}{*}{ Protección selectiva (elementos o valores) } & Grado parcial & Aumento de alturas \\
\hline & Grado ambiental & Sustitución y reproducción armonizada \\
\hline
\end{tabular}

Fuente: Plan General de Ordenación Urbana, fichas de elementos protegidos, <www-2.munimadrid.es/urbanismo_inter/visulaizador>.

colisión entre hábitat y ocio masivo) tienden a agotar el modelo, de manera que la recuperación se ralentiza, queda inconclusa o no llega a las zonas situadas al fondo, mientras reaparece con fuerza la prostitución callejera y asoma el riesgo de masificación turística. La incertidumbre económica y su correlato, la volatilidad, traducida muy reveladoramente en el cierre de la tienda National Geographic, abierta hace dos años, obligan a reelaborar parcialmente las estrategias pero dentro de una misma metodología.

\section{LA INSUFICIENTE PROTECCIÓN DEL PATRIMONIO}

Del millar largo de edificios sólo una quinta parte son construcciones modernas, salvaguardadas muy selectivamente sólo si están fechadas antes de 1960. El nivel de conservación es bueno, excepto al borde de la Gran Vía, donde la renovación desarrollista vinculada al sector terciario (plazas de Santo Domingo, Luna y Callao) fue más intensiva o más visible por el tamaño de las fincas y el grado de alteración paisajística, impacto que no produjeron las torres y grandes bloques de la autarquía (Montera, San Bernardo, Santo Domingo) dentro de su contexto. Fuera de ahí sólo hay sustitución generacional en forma de punteado, así que el $78 \%$ de los inmuebles posee dimensión histórica, interés patrimonial o responsabilidad en la definición del ambiente urbano tradicional. Los diez BIC declarados (tres palacios y lo demás construcciones religiosas) no permiten hablar de monumentalidad pero sí de indudable nobleza en San Bernardo, y el resto esmaltan un valioso conjunto de casas esencialmente alfonsinas, armadas acaso sobre soportes precedentes. El catálogo del plan general de 1997, en la edición original de las normas urbanísticas y en la actualización de
2014, jerarquiza esa edificación predominante (Cuadro I) mediante tres niveles de protección que se desdoblan en seis grados decrecientes con tratamiento diferenciado. La Gran Vía recibe trato preferente, pues casi el $60 \%$ de su arquitectura fue calificada con el nivel 1, porcentaje que asciende al $87 \%$ si sumamos los elementos del nivel 2 (protección estructural), y sólo en una decena de inmuebles están previstas intervenciones mayores. Al salir de ella el tratamiento se relaja un tanto, desde el momento en que los grados de protección singular e integral apenas superan conjuntamente el $8 \%$ de los edificios catalogados, poco más de un tercio figura en el nivel intermedio y los menos protegidos rebasan el $52 \%$.

El catálogo y las normas zonales para el Área de Planeamiento Específico del Centro Histórico contienen determinaciones, parcialmente vinculadas a las categorías de protección, acerca del parcelario, los espacios libres interiores y el uso de la edificación. Los cambios en la morfología catastral han estado prohibidos, no siendo para restablecer las divisiones parcelarias del pasado, pero a partir de 2014 sí se pueden agregar fincas, en cualquier nivel de protección, tramitando un plan especial. Se facilita la reordenación interna de los edificios y la intensificación del uso, en proporción inversa a la categoría de catalogación, de manera que en el grado integral un inmueble puede fraccionarse en viviendas no inferiores a $90 \mathrm{~m}^{2}$ útiles y que no dupliquen las unidades previas, sin contar las infraviviendas (por debajo de $38 \mathrm{~m}^{2}$ o claramente insalubres), susceptibles de adición a esos efectos. En el grado estructural el umbral de partición cae hasta los $60 \mathrm{~m}^{2}$ útiles, aunque en cada planta cabe al menos un apartamento o estudio más chico, y las condiciones se relajan cuando se trata de protección pública, pero incluso en el grado singular puede ser aceptable el sobre aprovechamiento, por la vía del plan especial. La nueva defini- 
ción interna supone a menudo mover y redimensionar los espacios descubiertos, con miras al esponjamiento de la trama. En un total de veinticinco manzanas se han fijado a ese fin alineaciones que suministran un patio central, suma de los individuales relocalizados. De forma parcial, vinculada a veces con el derribo de infravivienda interior, esa oxigenación ha llegado a esbozarse en algunas manzanas. Se prioriza el uso residencial pero con un régimen laxo de compatibilidades y cambios de función, así que las oficinas son autorizables como destino exclusivo al borde de las calles principales, desde 1997, y a partir de 2014 cabe la actividad hotelera en los niveles de protección 1 y $2^{2}$.

Al trasladar el catálogo al plano, para valorarlo espacialmente, se ve que sólo en la cuarta parte de las vías públicas, incluyendo algunas de primer orden como Hortaleza o Preciados, hay proporcionalidad entre tipologías. En cuanto al resto, pueden establecerse dos grupos. El primero está compuesto por una veintena de calles (29\% del total) altamente preservadas, donde al menos seis por cada diez edificios fichados corresponden a las categorías singular, integral o estructural. Se reparten regularmente en función del valor objetivable de su patrimonio, que forma conjuntos o al menos frentes de manzana (Estrella, Barbieri, Libertad, Puebla), cuando no consta de elementos sueltos dentro de entornos renovados (plaza Santo Domingo). En contrapartida prácticamente la mitad de los viales tienen un $60 \%$ o más de sus edificios sujetos a niveles de protección inferiores, el parcial predominando en catorce calles, y conjuntamente con el ambiental en otras veintitrés, que podríamos llamar «francas». Se abren así expectativas para transformar (o secundariamente demoler) alrededor de cuatrocientas casas antiguas en zonas de elevada rentabilidad potencial. El mayor claro engloba calles que drenan a Gran Vía (San Bernardo, Montera), la trasera de ésta y en términos generales el barrio bohemio de Universidad o Malasaña, con problemas heredados (deterioro, descapitalización) en vías de reversión por efecto de las áreas de rehabilitación integral, los nuevos ejes de actividad, el ocio o la gentrificación. Las manchas secundarias de menor protección están en Chueca (San Marcos, Barbieri), que aparte de su propio interés como barrio de diversión asociado al mundo gay aprovecha el prestigio de la zona inmediata a Gran Vía (Reina, Infantas), y también las transversales

\footnotetext{
${ }^{2}$ Ya en 2005 la Federación Regional de Asociaciones de Vecinos, en sus Propuestas Estratégicas para el Centro Histórico de Madrid (p. 21), cuestionaba ese estímulo a la terciarización.
}

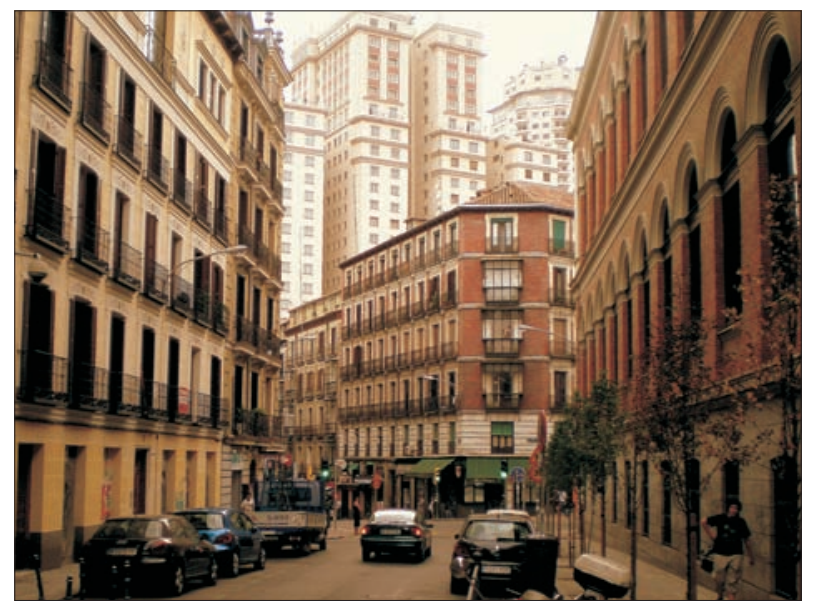

FIG. 3. Traseras del Edificio España, en el barrio de Amaniel (2012).

de Montera (Aduana, Jardines, Caballero de Gracia), que en parte formaban un enclave incongruente con su medio, como la Costanilla de los Ángeles o Caños del Peral cerca del Teatro Real.

Más de un centenar de establecimientos comerciales (el $80 \%$ fuera de la Gran Vía) fueron catalogados en tres niveles, para impedir su desvirtuación al acoger nuevos usos o actividades. Casi un tercio son de gran valor (17 en la Gran Vía), por lo tanto apenas hay lugar para obras en ellos, pero la gradación aplicada amplía las posibilidades de intervenir especialmente en el nivel 3, donde el local sólo es interesante o de carácter ambiental. Por fin, de los ocho espacios públicos existentes únicamente las plazas de Santo Domingo y Vázquez de Mella carecen de protección. Las de Callao, Carmen, Descalzas, España y San Martín caen bajo el régimen de parque o jardín protegido, en calidad de verde básico, aunque en algunos casos su botánica es insignificante, con nivel 3 . Todas poseen atributos favorables pero padecen impactos visuales, permitiéndose en ellas obras bajo rasante de carácter parcial, respetuosas con los espacios vegetales. Dada su alteración, la plaza Torres Acosta figura en el nivel 4 , donde las obras subterráneas pueden extenderse a la totalidad.

Revisables cuatrienalmente, los catálogos admiten el establecimiento de excepciones a través de planes parciales, que a partir de 2014 pueden regular la excavación de sótanos y reparcelación. En diversos documentos de planeamiento (Plan de Calidad del Paisaje, 2009c; Plan de Acción para la Revitalización del Centro Urbano, 2010b; Proyecto Madrid Centro, 2011a) se recoge la necesidad de rehacer el catálogo de edificios, tachado de excesivamente conservacionista, suavizando la protección para 
dar paso a nuevos tipos constructivos. Sin embargo en 2005 la Federación de Asociaciones de Vecinos denunciaba que «ha sido objeto de continuas descatalogaciones, o reducciones de nivel y grado « (Propuestas estratégicas para el centro histórico de Madrid, 2005, p. 62). La revisión del plan general llevó a adjudicar en 2012 la realización de un nuevo catálogo, cuyo avance se presentó en 2014, a falta de las fichas particulares.

\section{LA REHABILITACIÓN EDIFICATORIA: LA INTERVENCIÓN PÚBLICA Y LA INICIATIVA PRIVADA}

El plan general de 1997 fomentó la función residencial pero marcando distancia con los postulados de rehabilitación integral asumidos al comienzo del periodo democrático, que teóricamente daban protagonismo a la iniciativa oficial y priorizaban los intereses de la comunidad. A finales de siglo, coincidiendo con el inicio de un ciclo inmobiliario alcista, las nuevas coordenadas ideológicas, económicas y urbanísticas obligaban a compatibilizar las exigencias de mercado y los objetivos de desarrollo sostenible, algo más fácil de alcanzar en el discurso que en la realidad. La acción pública se orientó al patrimonio monumental y la financiación de reformas menores o tratamiento de fachadas en edificios civiles, aparte de las inversiones en infraestructuras y equipamientos, logrando mejoras ambientales de cierto alcance. Con ellas se creó plusvalor inmobiliario, recogido en gran medida por el sector privado, que fue adquiriendo un papel dominante en la rehabilitación o transformación de inmuebles completos, para vivienda en propiedad o terciario, según los principios neoliberales. El sobreprecio de pisos y locales comenzó a seleccionar actividades y residentes, creando conflictos que se sumaron a los problemas ocasionados por la eclosión del ocio nocturno. Allí donde no había expectativas suficientes aparecieron procesos de gueto con deterioro material, inmigración, negocios étnicos y localmente ocio marginal (Justo, 2011, pp. 74-78; Ezquiaga, Barros y Peribáñez, 2013,p. 105).

Los sucesivos proyectos alumbrados entre 2008 y 2010 por desarrollo o rectificación del plan de 1997, desde el planeamiento estratégico al de intervención en los distintos ejes (Gran Vía, Quevedo-Benavente), pertenecen ya a un contexto de crisis y por tanto a una etapa diferente (García Pérez, 2014, pp. 84-85). Defienden como principio general la mezcla de usos, por vía de reciclaje o sustitución, y ratifican con matices el objetivo de la rehabilitación residencial, viéndolo como tarea mixta público-privada para cualificar el centro histórico, rejuvenecerlo y lograr mayor variedad social, a partir del alquiler. El deseo de flexibilidad lleva a considerar que la condición previa sería suavizar las restricciones heredadas del catálogo de edificios protegidos. De todos modos, las fichas individuales pueden modificarse en cuanto lo requiere la lucha contra la infravivienda, problema muy presente todavía en 2010 dentro del área de reestructuración urbana formada por las bocacalles de Montera, donde el $13 \%$ de las casas tenían más de un $40 \%$ de alojamientos sin dimensión mínima, interiores o insalubres, según el Plan de acción para la revitalización del centro urbano (2010b, pp. 182-183). La estrategia culmina con el aumento de escala de las inversiones efectuadas por la Administración, su fortalecimiento y parcial reorientación hacia un urbanismo formal o de imagen. Se modela así el tablero de juego para atraer, en condiciones de liberalización, a un empresariado que se repliega al perder interés la periferia, ensayando en el centro estrategias renovadas (diversidad de formas de tenencia, gentrificación económica y residencial programadas conjuntamente, seguridad). El uso del ideario de la sostenibilidad es ambivalente, pues lo mismo sirve para suministrar algunas respuestas correctas (movilidad, arbolado) que como cortina de humo o coartada para una acción empresarial masiva cuyos actores son globales y locales. El avance de la revisión del plan general, presentado en 2013, parece profundizar en el modelo desregulador para la ciudad heredada, aunque no verá la luz a corto plazo.

El origen de las áreas de rehabilitación integral o preferente se remonta a 1994, pero su materialización definitiva se produjo a partir de 2003, según el mapa de Ezquiaga, Barros y Peribáñez (2013, p. 125), donde todo el reborde septentrional de Gran Vía y el barrio de Santo Domingo caen bajo ese régimen, que según los autores tiene sobre todo efecto en la envolvente de los inmuebles. Hasta el siglo XXI únicamente se habían producido intervenciones dispersas, epidérmicas o profundas, de manera que el Censo de 2001 recogió, en nueve de las dieciséis secciones censales estudiadas, porcentajes de viviendas vacías entre $28 \%$ y $32 \%$, disparadas hasta el $40 \%$ en Las Cortes y el $56 \%$ en la parte baja de Malasaña. A la altura del 2004, según afirmaba en una entrevista el concejal de Vivienda, Sigfrido Herráez, ya se veían los frutos en el entorno de Hortaleza, tres años antes de poner en marcha el mayor ARI (Pez-Luna, 1.197 viviendas) precisamente en ese ámbito de fuerte desocupación. Chueca, Pez-Luna, Montera y Mostenses van a ser los centros de interés donde la Administración ha concedido ayudas, para mejoras exteriores o de habitabilidad y para la adecuación 
de viviendas y locales pertenecientes a particulares, hasta 2008, en que reorienta sus inversiones hacia la eficiencia energética (Ayuntamiento de Madrid, 2009a, p. 348). La promoción privada corre con el grueso de las iniciativas en edificios completos, que deben vencer en ocasiones la resistencia de inquilinos o propietarios horizontales, pero cuentan con el aliciente de la intensificación de uso y la excavación de plantas para estacionamiento.

Desde 2005 hasta enero de 2015 se concedieron licencias urbanísticas para efectuar al menos 365 intervenciones, susceptibles de ser agrupadas por tipos de obras en dos grandes categorías, según impliquen o no la transformación del caserío heredado. El grupo mayor, tres cuartos del total, integra las diversas acciones de baja intensidad (restauración, conservación, consolidación) destinadas a impedir el deterioro, asegurar condiciones satisfactorias o recuperar si procede el estado original de los inmuebles. En gran medida guardan relación con la ITE, por tanto están muy repartidas y sus protagonistas suelen ser las comunidades de propietarios, frente a una fracción más reducida que corre a cargo de agentes inmobiliarios, constructoras, bancos o aseguradoras, cuyo campo se localiza en las partes más valoradas. A esa familia pertenecen también las obras exteriores, que sólo incluyen modificaciones menores (nunca de los volúmenes), realizadas a menudo por las sociedades comerciales o de servicios en sus establecimientos y propiedades ${ }^{3}$.

Las noventa licencias restantes autorizaron actuaciones con alcance superior, aunque sólo un diez por ciento de ellas dieron lugar a construcciones de nueva planta o ampliaciones. Las demás responden en su mayoría a las clases definidas en las normas urbanísticas del plan general de 1997 como rehabilitación, y dentro de ella acondicionamiento o reestructuración. Rehabilitar, y sus derivadas, tiene un sentido de adaptar y tratar patologías mediante obras de mejora que cambian la distribución de un edificio y pueden modificar su morfología y estructura. En una decena de permisos se menciona expresamente el incremento de la cantidad de alojamientos o la transformación de locales en viviendas, pero lo predominante es el acondicionamiento general (27 inmuebles), que no

\footnotetext{
${ }^{3}$ Jerarquizar y seleccionar las licencias fue una tarea delicada, por aparecer entremezcladas obras de muy dispar envergadura, parte de las cuales eran menores, por lo cual se rechazaron. Hubo que eliminar la duplicación de datos, en los edificios de varios portales o que hacen esquina y tienen la dirección postal de dos calles. Cuando aparecen varias licencias en un mismo inmueble se tomaron las de mayor entidad, y en caso de repetirse idéntica o parecida solicitud se recogió exclusivamente la última. En ocasiones la licencia de primera ocupación es la más explicativa acerca de la naturaleza de las obras, pero no siempre está disponible.
}

altera la morfología ni los componentes de interés como tampoco afecta a las bases de su composición interna y elementos comunes, aunque sí intensifica el uso al dividir el espacio. Los cambios en la organización interior, hasta alcanzar el vaciado, sí se producen en el grupo de quince edificios sometidos a reestructuración, mientras la rehabilitación con acondicionamiento parcial o puntual se da en otros ocho. La fuente consultada (el sIG municipal de Urbanismo) proporciona en cada expediente los datos del titular, la dirección y objeto de la licencia así como el uso principal resultante. Éste es residencial en un $60 \%$ del total, valor que responde al modelo de intervención aplicado en el distrito Centro, pero también obedece, a partir de 2008, a la crisis, que contrae en ciertas calles las expectativas de crecimiento del sector terciario, el otro pilar de la capitalización. Aun así, los servicios se mantienen como función primordial en casi cuatro por cada diez solicitudes, fundamentalmente a causa del enorme protagonismo de la hostelería de alojamiento. La distribución geográfica del conjunto de licencias tiende a un reparto proporcionado, ya que la Gran Vía y sus bocacalles menores suman un tercio, y el resto se reparte mayormente entre los principales ejes (Carmen, Preciados, Fuencarral, Montera, San Bernardo), las áreas de rehabilitación de Pez-Luna y Triángulo Ballesta (en adelante Triball, a la que nos referimos luego), además de Chueca y Santo Domingo.

Aparte de las empresas hoteleras, son contados los promotores que intervienen en más de una ocasión, al menos repitiendo nombre. La atomización, traducida en medio centenar de razones sociales diferentes, es, verosímilmente, más aparente que real, pero no resulta fácil establecer conexiones e identificar las diferentes denominaciones con que operan los grandes grupos. Entre éstos aparecen al menos Rehabitar Gestión, artífice del proyecto Triball'; Cerep (Carlyle), como representación de los inversores extranjeros; Larvín, ejemplo de los que tienen allí sus oficinas; Hercesa Inmobiliaria o el grupo de origen abulense Ventero Muñoz. No figura en cambio OHL, a pesar de su obra en Gran Vía, 80. Participan, por otro lado, sociedades vinculadas a Galicia (Valmarcasa, Vázquez Peña), a Euskadi (Rehabilitaciones Singulares, del grupo Sandamendi) o a Zaragoza (Inmuebles Postigo). En cuanto al resto, hay promotores, contratistas, constructores, agentes inmobiliarios dedicados a la adquisición, venta o administración de bienes raíces, o más

\footnotetext{
${ }^{4}$ Cfr. «Abandono, especulación, expulsión: gentrificación. El caso Triball en números», en Todo por la Praxis, 20 de diciembre de 2013.
} 
específicamente a la rehabilitación y el alquiler, además de empresas pequeñas con carácter reciente y que a veces fijan su sede o domicilio en la zona. Un grupo aparte lo componen las sociedades comerciales y de servicios terciarios, desde asesorías, turoperadores y agencias inmobiliarias hasta la hostelería gastronómica o los espectáculos, que intervienen para establecerse o ampliar y modernizar sus instalaciones, al igual que lo hacen bancos y organismos oficiales ${ }^{5}$.

Sólo una parte de aquella actividad aflora en las 15.165 viviendas del Censo de 2011, apenas un $3 \%$ más que diez años antes. Ese valor confirma la estabilidad de algunas secciones censales (Valverde, Fomento, Reina), cuyo dinamismo es posterior, pero más bien debemos entenderlo como la media resultante (y enmascaradora) de contrastes considerables, a pequeña escala, entre los lugares donde aumenta y donde disminuye el volumen de alojamientos. Las mayores pérdidas parecen estar relacionadas con la intensidad de la terciarización (-26\% entre Fuencarral y Hortaleza; $-11 \%$ en la plaza de Santo Domingo) y también con la reestructuración de áreas degradadas (-20\% entre Montera, Caballero de Gracia, Jardines y Aduana). Ahora bien, esos procesos regeneradores en el marco de las ARI producen el efecto contrario en Malasaña, donde el ámbito de Pez-Luna y Triball incrementó casi un tercio su parque residencial, y entre Luna-San Bernardo y Gran Vía alcanza casi el $38 \%$. Su equivalente en Chueca, la sección censal comprendida entre Vázquez de Mella y San Marcos, apenas rebasaba el $14 \%$.

El trabajo de campo sistemático realizado en agosto y diciembre de 2014 a fin de completar los datos precedentes y hacer balance de la rehabilitación edificatoria permitió contabilizar 591 casas con alguna clase de inversión perceptible exteriormente. El $60 \%$ son intervenciones someras o realizadas hace cierto tiempo, y se reparten consiguiendo un nivel de conservación de fachadas bastante homogéneo, excepto en algunos rincones del barrio de Amaniel. El $40 \%$ restante comprende 240 edificios donde a simple vista se han efectuado rehabilitaciones o transformaciones más profundas o más recientes, y casi tres de cada cuatro están en la orla septentrional de la Gran Vía, donde Corredera y Valverde (los tramos incluidos en el área analizada) tienen más de diez intervenciones (15 en Gran Vía), y otras quince calles reúnen entre cinco y diez. La mayor concentración de inversiones se produce en Malasaña, con 57 edificios en la parte articu-

\footnotetext{
${ }^{5}$ Esos datos proceden de <www.expansion.com>. [Consulta: 25-01-2015.]
}

lada por las calles Estrella-Luna-Pez, y 42 en Triángulo Ballesta. El segundo núcleo se sitúa en Chueca, donde Fuencarral con sus transversales suma 16 actuaciones, y otras 15 entre San Marcos, Libertad y Barbieri; un foco menor alcanza la decena de inmuebles entre Montera y sus tributarias Aduana y Jardines.

Al salir de la Gran Vía la evolución reciente no está desprovista de paradojas, pues el declive de los grandes desarrollos inmobiliarios favorece la concentración empresarial y geográfica, pero existe una relativa saturación del mercado al menos con las fórmulas clásicas de rehabilitación de lujo, cuyos precios pueden resultar incongruentes con el ambiente o las condiciones objetivas del lugar, y de hecho en cuanto se sale de los principales itinerarios hay una distancia considerable respecto a las zonas más caras de Madrid. Al menos en una decena de calles y plazas son muy numerosos los locales y viviendas para arrendar, sin salida aparente, según el cómputo efectuado en marzo de 2015, que permitió registrar ofertas de alquiler por temporada, para largas y cortas estancias, por ejemplo en zonas de movida. De otro lado, el tipo de obras habitual no suele asegurar un nivel de conservación suficiente, raramente incurre en recrecimientos abusivos (una a tres alturas), pero sí practica con frecuencia el vaciado o el fachadismo, habiendo ejemplos claros de artificiosidad, por ejemplo en la cuesta de Santo Domingo. Es fácil apreciar intervenciones más correctas en buen número de arterias al norte (Corredera, Estrella, Luna, Pez, Pizarro, San Roque) y al sur (Jardines, Veneras) de Gran Vía, frente a otras partes rezagadas, en expectativa o relativamente al margen, dado que hay diferentes velocidades y comportamientos dispares. Incluso allí donde cabe hablar con propiedad de rehabilitación las mejoras parecen producirse edificio a edificio, en acciones sueltas u operaciones aisladas más que regeneración de piezas completas. Cuando el ritmo se ralentiza o la actividad desaparece, queda una transformación incompleta, con marcados contrastes sociales y económicos. Diversificar soluciones, tal y como se propugna por ejemplo en el proyecto Madrid Centro (2011a), parece un camino adecuado, aunque hasta el momento apenas ha habido experiencias innovadoras, como la controvertida conversión de locales en lofts, dentro del área de estudio.

Las lonas tratadas como soporte publicitario, protegiendo edificios en reforma o reestructuración, han pasado a formar parte de la imagen de la Gran Vía, en cuyo primer y segundo tramo se percibe más fácilmente el efecto de las obras, aunque en el tercero se ha producido el único derribo (número 48), fruto de la operación significativamente denominada Gran Vía Capital, del grupo 
coruñés Valmarcasa, así como la transformación interna del número 68 , iniciada por la sociedad de riesgo norteamericana Cerep-Carlyle, y la del número 80 , debida a OHL. Las expectativas despertadas por la promoción de hoteles, despachos para profesionales, viviendas exclusivas, locales comerciales y párquines subterráneos atrajeron como ya se ha dicho el interés de los inversores, desde Caixa Nova a seguros Axa, Arproma (en la cual participaba la corporación financiera Caja Madrid) y finalmente Amancio Ortega, que accedió en 2015 a la propiedad del Madrid-París (número 22). Unos adquirieron con idea de volver a vender y otros para modernizar los inmuebles y luego alquilar o transferir la propiedad por fracciones, llegándose en 2014 según el portal <www. idealista.com $>$ a un récord de valoración (veinte mil euros por metro cuadrado) en el número $37^{6}$.

$\mathrm{Si}$ ayer tuvieron relevancia las restauraciones destinadas a alojar instituciones públicas, ahora lo más destacado es el cambio parcial de uso para comercio de franquicias o servicios terciarios, y la adaptación de edificios de viviendas como hoteles, en cinco casos desde 1995. Se excavan hasta cinco plantas de estacionamiento subterráneo (números 68,48 ) para apoyo de nuevas oficinas y alojamientos, pues va imponiéndose la multifunción, con cabida de usos residenciales que en algún caso incrementan el número de unidades de partida. Por lo que respecta a la naturaleza de las obras, se conservan fachadas y elementos estructurantes o bien hay demolición interior completa (números 4, 18). En 2010 Fernández Ramírez, González García y Morán Alonso (p. 43) registraban trece experiencias (incluyendo el área aledaña) de reordenación interna para adecuar a funciones distintas de la original, y adelantaban la remodelación del edificio España (p. 46), pendiente aún hoy del proyecto definitivo, aunque se anuncia un espacio comercial que trasladaría el centro de gravedad desde la mitad oriental de la Gran Vía hacia Poniente. No todas las propuestas han llegado a cristalizar, pues por ejemplo la adecuación del Palacio de la Música para auditorio vio sus obras interrumpidas en 2012. Por otra parte, las casas de mayor alzado son a veces verdaderos laberintos verticales que, a pesar de su vetustez y parcial desocupación, no han posibilitado actuación alguna a causa de la propiedad atomizada o la nube de negocios instalados en ellas. Tanto los datos del COAM como las licencias urbanísticas (desde 2005) y el

\footnotetext{
${ }^{6}$ Equipo: «Axa compra por 80 millones el n. ${ }^{\circ} 37$ de la Gran Vía (Madrid)», Idealista/news, Información sobre vivienda y economía (<www.idealista.com $>$ ). [Consulta: 23-01-2015.] En cuanto a Cerep-Carlyle y Arproma, véase Ortín Ramón (2012) y Cámara de Cuentas de la Comunidad de Madrid (2006).
}

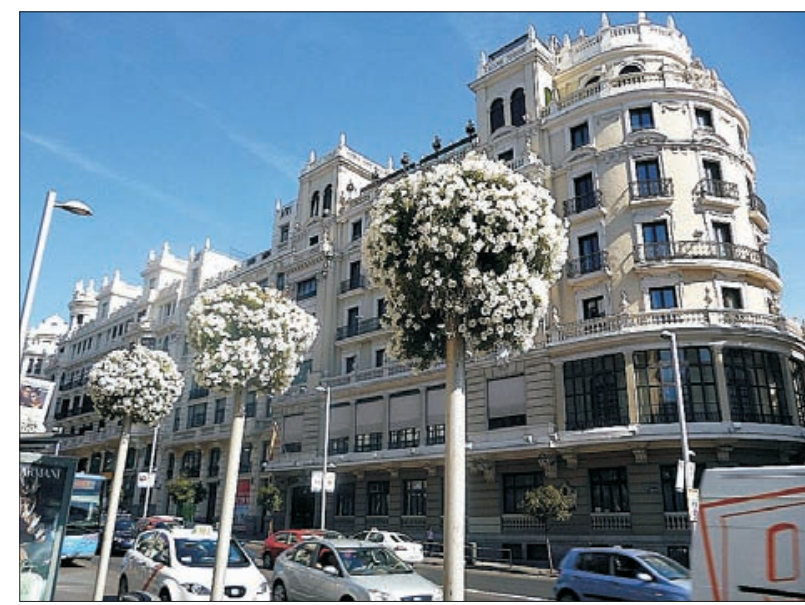

FIG. 4. Los nuevos usos más cualificados tienden a colonizar el primer tramo de la Gran Vía, no sin cierta dificultad de salida, hasta el momento, en el caso de las oficinas.

resultado de la última inspección visual sobre el terreno a comienzos de 2015 cifran en algo más de una veintena las intervenciones de mayor entidad que, sumadas al simple tratamiento de fachadas, sólo permiten hablar de un moderado deterioro exterior en algunas edificaciones del tramo final. Ahora bien, el proceso de reocupación de la avenida parece un tanto ralentizado por la crisis, los precios disuasorios $\mathrm{u}$ otros factores, de manera que se ofrecen más de veinte bajos y locales en planta, y están disponibles para el alquiler, a la fecha de redactar este texto, dos edificios casi completos transformados hace relativamente poco tiempo (números 1 , Grassy, y 4, antiguo Banco Urquijo).

\section{EL ESPACIO PÚBLICO Y LOS ASPECTOS AMBIENTALES}

Entendemos por rehabilitación urbanística la inversión en instalaciones, redes técnicas, espacios libres y movilidad (Plan de acción para la revitalización del centro urbano, 2004, p. 211; Ayuntamiento de Madrid, $2009 b$, p. 189). Iniciada a finales del siglo xx, se extendió desde los principales ejes a las ARI, especialmente entre 2005 y 2010 (Fernández Ramírez, González García y Morán Alonso, 2010, p. 40; Justo, 2011, p. 77). Su finalidad es doble, pues equipa y eleva las condiciones de habitabilidad en un medio difícil por la vetustez, densidad edificatoria, baja permeabilidad de la trama y escasa vegetación, sometido a una presión de uso que provoca diversos impactos (residuos, ruido, descarga de mercan- 
cías, tránsito, estacionamiento) y agudiza el efecto isla de calor (Proyecto Madrid Centro, 2011a, p. 27). Por otra parte, se trabaja con la metodología de intervención estratégica que obliga a cultivar la imagen de marca, fomentar la cultura y acomodar el entorno a los patrones renovados de ocio y consumo (Plan de Calidad del Paisaje, 2009c, p. 11; CAM/CEIM, 2010, p. 81). El objetivo es generar plusvalor, con recursos públicos, a beneficio del turismo y las demás actividades empresariales (Justo, 2011, p. 76; García Pérez, 2014, pp. 74 y 77-78). Eso obliga a solventar los problemas de degradación (grafitis, movida, proxenetismo) e inseguridad (hurtos, tráfico de drogas) denunciados de forma recurrente incluso en 2010 y 2013, cuando el modelo de intervención adoptado trae consigo otras formas de deterioro (exceso de terrazas y puestos de venta) ${ }^{7}$.

Algunas actuaciones merecen la consideración de buenas prácticas, pero también caben dudas razonables sobre el planteamiento de ciertas obras, su elevado coste y su trasfondo político, dado que no necesariamente garantizan un efecto regenerador cuando se quedan en la superficie o buscan sobre todo el embellecimiento, para revalorizar las propiedades facilitando su explotación económica. El nivel básico es el de las instalaciones y redes técnicas, como iluminación o contenedores, al que se agrega la renovación de infraestructuras en superficie y ahí entra la pavimentación, por tanto las decisiones para compatibilizar movilidades, el verde y el mobiliario (Área de Gobierno del Ayuntamiento, 2009a, pp. 353354). En los grandes recorridos peatonales se utilizaron losas de granito, material que en viales más estrechos o de coexistencia queda reducido a las aceras, ensanchadas cuando es posible o enrasadas con la calzada, suprimiendo el bordillo. Para las zonas de rodadura o estacionamiento se usó normalmente el adoquín de hormigón, cuya respuesta es insatisfactoria por encima de un cierto umbral de tránsito, así que aparecieron enseguida roderas, resquebrajaduras o hundimientos, obligando a reforzar el piso o sustituirlo por losas de piedra natural, fáciles de ensuciar. El mobiliario y las dotaciones, repartidos con arreglo a la categoría, latitud y modos de transporte que soporta cada calle, incluyen elementos de defensa que separan la acera de la calzada o protegen los árboles dispuestos rítmicamente dentro de los aparcamientos en cordón. Son bolas de piedra, bolardos y pivotes de metal

\footnotetext{
${ }^{7}$ Acibu (2010, s. p.); Federación de Comerciantes y Vecinos del Centro de Madrid (2013, pp. 12, 15, 21); Florencio (2013, s. p.); Hidalgo (2013, s. p.) Se señalaba también la proliferación de motos estacionadas en la vía pública, la ocupación de las aceras por los contenedores y el porte bajo de los árboles de alineación.
}

que producen un impacto visual considerable al formar a veces interminables hileras, aparte del efecto barrera y peligro de caídas. Con menor frecuencia pueden verse jardineras de hormigón en la calzada o paralelepípedos de granito con función de incómodos asientos, mientras los paneles publicitarios se reservan a sitios de mucho público.

La propuesta del plan de 1997 para oxigenar la trama mediante nuevos patios generales («patios azules») sólo dio resultados puntuales; en cambio, la naturalización y despliegue de un sistema verde, objetivo reafirmado en el avance de la revisión del plan (2013), se logró en las vías públicas a través de los árboles de alineación. Quedan pocos pies de arbolado con cierta edad o porte; sin embargo, las plantaciones, instituidas a finales del siglo $\mathrm{xx}$, se han extendido a más de sesenta calles, en su totalidad o de forma discontinua, aprovechando retranqueos. Cuando no es posible recrecer las aceras, su rebaja deja intercalar plantones en la franja de estacionamiento lineal, lo cual obliga a protegerlos con pivotes y aun así son difíciles de lograr a causa de los autos y el vandalismo. De ahí la imagen relativamente habitual de alcorques vacíos y el sobrecoste de reposición, cuyo lado positivo es la diversificación del repertorio de familias botánicas. En principio predominó el aligustre, que ya forma bóveda en ciertos tramos de calle, por su rápido crecimiento, escasa exigencia y alta contribución ornamental al ser perennifolio. El avance de la repoblación y la renovación de pies perdidos ha ampliado el número de especies hasta catorce, algunas tan vistosas como los hibiscos de flor malva o blanca, que a medio plazo darán riqueza florística al barrio ${ }^{8}$. En la Gran Vía, por el contrario, la reforma del cambio de siglos sustituyó los abundantes pies de aligustre y jardineras por barandillas de metal, postes coronados con macetas de flores y un número muy inferior de photinias, de manera que pasó a predominar la superficie granítica.

El otro pilar del desarrollo sostenible es la política de movilidad, consistente primero en el templado de tráfico y las peatonalizaciones selectivas, de grandes ejes y vías derivadas, conectados durante una segunda etapa hasta formar islas. La primera área de prioridad residencial (APR) declarada en 2004 afectó al triángulo Gran VíaClavel-Alcalá y, como resultado de las peatonalizaciones realizadas en gran medida antes de 2011, está previsto

\footnotetext{
${ }^{8}$ Hay perales, árboles del amor, catalpas, melias, ciruelos, tilos, castaños de indias o árboles chinos, según la página web municipal, <http://www.unalcorqueunarbol.cloudapp.net>.
} 
extender en 2015 la figura de APR a todo el reborde sur, al menos entre Callao y plaza de España. Exceptuando las ocho calles y plazas abiertas al tránsito, para acceder a los principales estacionamientos, la red arterial sólo admitirá allí el desplazamiento de los habitantes, la entrada de motos durante el día y la carga y descarga en horario de mañana que se estudia ampliar a la tarde. La fracción restante, entre Callao y Clavel, está en proyecto, al igual que la conversión en APR del flanco norte de la avenida, pero requiere ajustar el interés vecinal y las necesidades empresariales (Сеiм, 2009, p. 4). Ese modelo, que obliga también a crear plazas de aparcamiento en superficie para motocicletas, sirve de poco si no se potencia el transporte público y los modos no motorizados. Madrid ha estado un tanto al margen de los avances en movilidad sostenible hasta fecha reciente, careciendo por ejemplo de tranvía o metro ligero por el centro, pero dispone de una línea de minibuses alimentados con batería eléctrica (Sevilla-Argüelles) que se adentra en el tejido histórico. En cuanto a las bicicletas, el servicio municipal de vehículos eléctricos inaugurado en 2014 (Bicimad) dispone de nueve bases en el espacio estudiado, pero no proporciona la seguridad del carril bici, sino el dudoso planteamiento de las ciclo calles, donde los automóviles no pueden rebasar los $30 \mathrm{~km} / \mathrm{h}$.

Los lugares idóneos para el diagnóstico de conjunto son las diez plazas, dos de las cuales, Red de San Luis y Callao, articulan los tres segmentos de la Gran Vía, y la plaza de España resuelve su soldadura con el ensanche de Argüelles. Vinculadas otras a las propiedades religiosas y la reforma interior, Mostenses es sólo el entorno del mercado de abastos, mientras las demás han cumplido función de distribuidores (Santo Domingo) o desahogos (Carmen, Descalzas, Luna, Mesoneros Romanos, Vázquez de Mella). Excavadas desde los años setenta para construir estacionamientos subterráneos, o mixtos con altura sobre rasante, quedaron desnudas, devaluadas por los derribos y obra nueva con fuerte impacto, sin más excepciones que las del Carmen y Red de San Luis. A pesar de sus contrastes tipológicos las plazas DescalzasSan Martín y Luna son las únicas provistas de interés patrimonial, aunque Santo Domingo y Carmen tienen el aliciente de sus arquitecturas de posguerra afines a Gran Vía. Sin embargo el atributo de zona verde sólo sirve para la plaza de España, Carmen y relativamente Descalzas, Santo Domingo y Vázquez de Mella.

Recuperar esos espacios es un objetivo reiterado en todas las escalas de ordenación y proyectos concretos, desde el Plan de Calidad del Paisaje, donde se priorizaba su uso público (2009c, p. 13) hasta el Diagnóstico del Plan

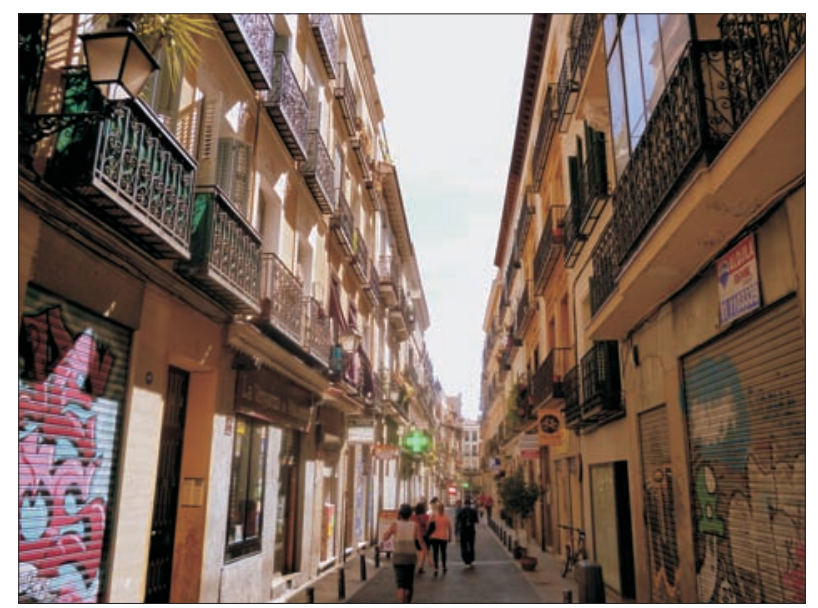

FIG. 5. La rehabilitación convierte el área deteriorada en beau quartier.

Director del Eje Gran Vía y su Entorno, que insistía en la función de estancia para los residentes (Fernández Ramírez, González García, Morán Alonso, 2010, p. 49). La reforma de la plaza Luna (también llamada Torres Acosta) marcó el comienzo de programas de intervención más ambiciosos, y por eso puso énfasis en la superación del mal ambiente y el deterioro social propios de un entorno dual (Almarza, 2010, s. p.; Ardura Urquiaga, 2014, p. 5; Plan estratégico de Pez-Luna, 2010a, p. 7). Ahora bien, Luna y Callao son el blanco habitual de las valoraciones negativas en cuanto al acondicionamiento y la gestión ${ }^{9}$. Normalmente inciden en el coste de unas obras no siempre necesarias, de gusto discutible, que reducen el verde frente a las zonas pavimentadas, introducen barreras y limitan la posibilidad de sentarse en bancos, al fomentar la proyección de la hostelería. Carpas, mercadillos, pistas de hielo, puestos, kioscos y especialmente terrazas, según combinaciones diversas de usos estacionales y permanentes, privatizan recintos cuyo alquiler es una vía ideal de monetarización (Ardura Urquiaga, 2014, pp. 4 y 11-14). Quedan no obstante algunos recintos frondosos (Carmen, Mesonero Romanos), y ejemplos de difícil regeneración como la de Santo Domingo, cuyo declive es salvado por muros de hormigón que cierran la parte aérea del parquin, y sin embargo su coronación está bien resuelta con áreas de asiento y juegos. El complemento de esas actuaciones en ámbitos de gran densidad mercantil o turística ha sido la búsqueda de unas condiciones de seguridad, a través de cuatro comisarías de policía nacional y local, más el dis-

\footnotetext{
9 García Gallo (2011, s. p.); Justo (2011, p. 78); Zabalbeascoa, citando a González Virós (2014, p. 30).
} 
positivo de video vigilancia que, activado en 2008, totalizaba seis años después 147 cámaras (Ruiz Chasco, 2014, p. 305). Su efecto, sumado a otras acciones, se percibe con nitidez en el caso de los grafitis, que todavía en 2012 tenían una incidencia de proporciones insoportables, y hoy están progresivamente relegados (los de carácter artístico o decorativo) a los cierres de las tiendas, aunque todavía afectan a los portales y algunos bajos.

\section{LA CONCENTRACIÓN SELECTIVA DE ACTIVIDADES}

\section{LOS USOS CENTRALES: PERMANENCIA Y RENOVACIÓN COMERCIAL}

La apertura de la Gran Vía reforzó el centro tradicional, convirtiendo una parte del mismo en su área de mayor afección, con los perfiles propios de una city (Alaminos López, 2009, p. 59). A pesar de la deslocalización, es todavía un medio económicamente muy espeso, rico en funciones no residenciales y usos institucionales, alojados éstos en un total de veinticinco edificios públicos que resultan más visibles en la confluencia con Alcalá y en San Bernardo. Son ministerios, consejerías del Gobierno regional y servicios municipales, entre otros organismos oficiales con distinto peso espacial y capacidad de atracción. Sumados al aparato burocrático existente en las inmediaciones, la dotación financiera y los recursos culturales o recreativos del entorno, ayudan a multiplicar la fuerza gravitatoria del comercio y los servicios, originando flujos de población intensos: según <www.tcstreets.com/es>, Gran Vía figura entre las rutas más animadas del país, con una media diaria superior a 12.000 personas en julio de 2014, y récords en torno a los 35.000 durante las rebajas. Tan fuerte concurrencia, traducida asimismo en el paso de más de 50.000 vehículos diarios, resulta indisociable del turismo, que trajo a la capital 4,5 millones de extranjeros en 2014. La fracción central, entre Clavel y Jacometrezo, junto con las manzanas situadas a mediodía, forma parte de la zona declarada de gran afluencia turística a efecto de horarios mercantiles.

A finales de 2014 el zócalo comercial de la Gran Vía reunía 175 negocios a pie de calle, fundamentalmente hoteles, firmas de moda, complementos y comida rápida, aunque subsisten siete teatros y cines de los trece existentes a finales del siglo pasado, y poco más de una quincena de comercios tradicionales (Fidalgo Monteagudo, 1996, p. 63). Contando las plantas altas se añaden dos tercios más de locales, con variedad de cometidos. En 2010
Monumenta Madrid atribuía a la mitad de los inmuebles dedicaciones mixtas que incluyen tanto hostales como servicios personales y despachos de profesionales. Desde entonces las oficinas se han abierto paso con la rehabilitación, en contraste con otros barrios cercanos, donde tienden a estancarse o disminuir en beneficio de la periferia (Sanz López, 2011, p. 11). Las diferencias entre las tres secciones de la avenida, bastante marcadas antaño, van desdibujándose, pues el primer tramo, caracterizado por los bancos, edificios públicos y tiendas especializadas, es invadido por la restauración de calidad y las marcas, que ya colonizan la parte central (El Bulevar), dedicándola a las compras de impulso, cuya incorporación más reciente es Primark (prevista para 2015). En cambio, el codo de Callao y la bajada hacia la plaza de España conservan los espectáculos a cuyo calor florece la hostelería, en disputa con la función mercantil.

El Censo de Locales permite manejar cifras referidas específicamente al espacio estudiado, donde funcionan, en diciembre de 2014, 1.381 locales con puerta de calle y agrupados. Un $41 \%$ están al sur, del lado vertiente a Sol y Arenal, es decir las arterias reformadas en el siglo XIX (Montera, Preciados, Carmen), que siempre fueron las más tupidas comercialmente, como demuestran los grandes almacenes. Desde finales del siglo xx el centro de gravedad se ha movido hacia el norte (Fuencarral, Hortaleza), donde la fracción más joven del sector reúne casi un $60 \%$ de los establecimientos. Las transversales a Gran Vía (San Bernardo además de las citadas) y las paralelas vertebradoras de la trama (Pez, Infantas, Leganitos) son las más terciarizadas, y en general se registra mayor actividad allí donde hubo un mejor acoplamiento con el tejido histórico. En la porción que acumula más tiendas y empresas hay dos tiempos bien distintos: hasta muy entrada la mañana lo más llamativo es la descarga de mercancías y la presencia de cientos de furgonetas que congestionan las bocacalles. A partir de mediodía el ambiente de trabajo pierde relevancia ante los turistas y por las tardes, particularmente en fin de semana, se produce como antiguamente y de manera creciente el paseo, de nativos y visitantes, la afluencia a las terrazas y espacios públicos para celebrar, en torno a las compras y el ocio, la escenificación social prolongada en horario nocturno. Mas no todo es calle espectáculo, pues hay rincones y espacios de fondo que viven un tanto aparte, lugares de tempo lento donde aún domina el uso residencial incluso en los bajos y es poca la comercialidad (Amaniel, calles entre Luna y Pez, Fomento).

La dinámica actual, espontánea y planificada, en todas sus facetas (crecimiento, modernización, jerarquía, 
variación del reparto espacial), ocasiona una quiebra del modelo tradicional y en consecuencia la pérdida casi total del comercio heredado. Ya en 2010 el barrio Universidad era el único donde las empresas anteriores a 1940 lograban representar el $1 \%$ del total; en todo el reborde de la Gran Vía más del 44\% no superaban los diez años de edad. A velocidades diferentes desaparecieron los almacenes populares, negocios familiares, de tradición española (sederías, textiles, mantillas) o vinculados a las condiciones de consumo de otras épocas (sanatorio de muñecos). Han ido cerrando las tiendas de maletas y los colmados, pero también disminuyeron de modo sustancial la pequeña reparación y hasta las tiendas eróticas, residuales hoy como las de discos de vinilo. Se imponen nuevas orientaciones específicas en el Chinatown de Leganitos o las tiendas gays de Hortaleza, pero entre las viejas calles especializadas San Bernardo prácticamente perdió sus librerías, que permanecen testimonialmente en Libreros, afectadas, como los negocios supervivientes de Gran Vía, por la actualización de alquileres a finales de 2014. Dentro de ese contexto los pasajes y galerías formados desde el siglo XIX para extender los recorridos de escaparates tienen ahora escasa vitalidad: el pasaje Murga (1845) de la calle Montera, principal herencia mercantil en la zona de estudio, está en rehabilitación, albergando, como la Gran Galería de San Bernardo (edificio Los Sótanos, 1949), comercio o servicios de calidad regular (dieciocho establecimientos entre los dos), incluyendo chinos y compraventa de oro.

Se viene aplicando un patrón de desarrollo axial que potencia, mediante planes directores, los ejes mercantiles (particularmente en nuestro caso el Fuencarral-Montera) con esquemas propios de centro comercial abierto (Barómetro de economía, 2011, p. 128; Justo, 2011, p. 74). El sector de la distribución, enriquecido con nuevos atributos (diversidad, especialización), se comporta como vértice superior del triángulo de funciones centrales junto con la cultura y el ocio, en esos corredores que habrán de contribuir al crecimiento de las zonas cercanas (Plan estratégico Pez-Luna, 2010a, p. 15). A tal efecto los empresarios se ponen al frente de un proyecto de rehabilitación elitista para la trasera de Gran Vía (entre Corredera Baja de San Pablo y Valverde), respaldados por grupos amplios de residentes. Allí, la asociación de vecinos y comerciantes AC Triball (Triángulo Ballesta, que toma nombre de la calle más popular) utiliza una estrategia novedosa, pues su punto de partida será el despegue comercial, adquiriendo desde el año 2008 locales vacíos y burdeles para rehabilitarlos y ofrecerlos a empresas de calidad y estilo, englobadas bajo la ambigua marca
Okupación Creativa (Barómetro de Economía, 2008, p. 12). Liberan así al barrio de sus connotaciones negativas, entre las cuales no estaba ausente la peligrosidad, para seguir los pasos del Soho londinense o lograr un beau quartier que facilite la conquista residencial de clase (Justo, 2011, p. 78; Todo por la praxis, 2013, s. p.). Según Triball en 2013 la asociación ya se había hecho cargo de 190 locales y restaurado más de setenta, dedicados en parte a nuevas tendencias, negocio alternativo y ocio. Hasta 2015 los emprendedores suman una treintena de establecimientos (ropa, complementos, diseño), el $77 \%$ de ellos entre las calles Corredera, Barco y Ballesta, donde el experimento da sus mayores frutos, con fuerte participación de la hostelería. La corta vida de algunas tiendas chic, que pasan a engrosar la oferta de locales y pisos vacantes, parece indicar que las cosas no avanzan suficientemente rápido, y resulta difícil erradicar la prostitución de la calle Ballesta (Almarza, 2010, s. p.; Ardura Urquiaga, 2014, p. 5).

La llamada «gentrificación comercial», aún por debajo de las expectativas, establece fórmulas de modernización con criterios de exclusividad (tiendas vintage, retro, manga) para lograr calles amenas (Pez, Estrella, Hortaleza) donde se despliega la nueva imagen turística del centro. Predominan las zonas mixtas, donde los ajustes se producen de manera relativa o gradual, y parte de su comercio es corriente (étnico, de barrio, gay, servicios telefónicos), excepto en las arterias muy valoradas (Montera, Infantas, Pez) u objeto de reorientación (Corredera), que son más selectivas. De otro lado están las vías centrales de mayor homogeneidad o especialización, como Carmen o Preciados (la más cara en 2013 por alquiler de locales), con tiendas franquiciadas o multimarca, comercio masivo de capital local y empresas de oportunidad (compro oro). Pueden obedecer por completo a pautas de centro comercial abierto, caso de Fuencarral cuya expansión se produjo entre 1998 y 2006 (Sanabria Brassart; Torre Binimecis, 2000, p. 500). La brandificación (Muñoz, 2008, p. 12), entendida como sometimiento de esos ejes a las grandes firmas, trae consigo un resultado trivial o banalizador, por tanto incongruente con las previsiones (Сеiм, 2009, pp. 1-2; García Pérez, 2014, p. 86). $\mathrm{Al}$ reproducir la oferta genérica de los malls e incluso de las calles comerciales de barrio, el entorno no resulta favorecido, particularmente cuando las tiendas caras o de cierta rareza (mucho más frecuentes en el barrio de Salamanca que en Fuencarral) se mezclan con las de descuento y outlet, vinculadas al diseño pero seriadas (Villanueva Cajide y Casas Lobo, 2010, s. p.; Federación de Comerciantes y Vecinos del Centro de Madrid, 2013, p. 


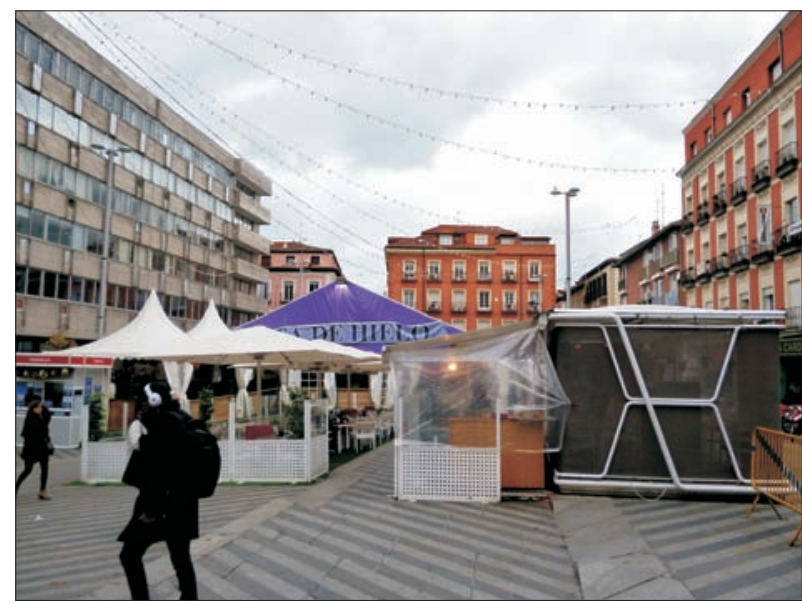

FIG. 6. Plaza Luna, la sobreexplotación del espacio público.

27). En el caso de Gran Vía la idea de la simplificación, utilizada por Fernández, Ramírez y Morán (2010, p. 40), es cierta, pero el dispositivo comercial tampoco carece de variedad. Los negocios de corte clásico regentados por asiáticos forman grupo aparte, están muy repartidos en forma aleatoria y tienden a la diversificación, desde los mayoristas a las peluquerías y alimentación (carnicería, frutería, pescadería por separado), reutilizando a menudo locales antiguos, incluso de las mismas tiendas de ultramarinos. Es un ejemplo característico de sucesión empresarial, que coloca a esa comunidad en cabeza de la pequeña distribución alimentaria, frente a los no muy numerosos supermercados de las cadenas Día y más recientemente Carrefour Express.

Son sobre todo las franquicias globales las que configuran el escenario del consumo, reforzado con la liberalización de horarios y días de apertura, hasta las veinticuatro horas en el caso de MacDonald's. El proyecto Escenas Encendidas (2010) autorizó, en principio a los cines y teatros, la colocación de enormes pantallas en movimiento, sucesoras de los viejos carteles, al estilo anglosajón o japonés. Pero el pretexto cultural ya no sirve para los nuevos leds, más de una veintena de paneles electrónicos de dimensiones diversas, informativos o en su mayoría puramente publicitarios, demostrativos del poder de las grandes compañías y en particular las empresas de telefonía, una de las cuales, Vodafone, ha logrado situarse en lo alto del edificio Capitol, del mismo modo que se incorporó como apellido en la estación de metro Sol-Vodafone y como distintivo de la línea 2. La propaganda comercial camufla la dimensión histórica y el interés patrimonial del bulevar, terminando de empobrecer unos estilos de vida volcados al ocio y el consumo.
Desde 2008 el pinchazo de la burbuja inmobiliaria, interrelacionado con la crisis financiera y económica, ha incrementado exponencialmente la desocupación de locales y oficinas, incluso edificios completos como el Caja Monte (Peligros esquina Jardines). Parte de ese fondo, más numeroso en zonas con arquitectura elevada, lleva más de seis meses disponible, intervalo durante el cual ha saltado en parte de la venta al alquiler. Al menos en una decena de calles son numerosos los locales anunciados («quemados» en el lenguaje común), de larga duración o cerrados hace tiempo, que llegan a sumar hasta cinco o siete seguidos (Infantas, Caballero de Gracia). Signo de los tiempos, la inestabilidad acorta el ciclo de vida o acelera el ritmo de sustitución de las tiendas (locutorios, comida hecha, productos dietéticos), incluso negocios nuevos de diseño que en el mejor de los casos se mueven a sitios más baratos y abren locales más básicos, por si no consiguen una perdurabilidad. Viceversa, la falta de aliciente para las grandes inversiones deja un hueco al comercio de proximidad, pero sólo en vías secundarias pues en las de primer orden la volatilidad obra a favor de los monopolios. Así sucede en Fuencarral, que desde finales del siglo xx y a raíz de su peatonalización se convirtió en lugar muy frecuentado por los jóvenes, patrocinadores en parte del nuevo comercio original, que formó una ruta cargada de vistosidad, entre Malasaña y Chueca. Esas tiendas y talleres comenzaron a ceder ante las franquicias (corrientes o selectas) ya en 2008, iniciándose una reconversión que borra las señas de identidad, formando un pasillo tanto más visitado cuanto más despersonalizado (Barómetro de Economía, 2008, p. 111). El proceso culmina con el cierre del mercado de Fuencarral (34 tiendas de moda), anunciado para 2015, a beneficio de una multinacional textil.

\section{LA FORMIDABLE EXPANSIÓN DE LA HOSTELERÍA}

Entre 1998 y 2014 el mayor incremento del número de negocios hosteleros se produjo en las dos zonas de ocio situadas al norte de la Gran Vía: $20 \%$ en Universidad-Malasaña, donde funcionan 551 locales con acceso desde la calle, y más del $31 \%$ en Justicia-Chueca, que reúne 460. Al sur los valores se moderan (19\% en Cortes, $14 \%$ en Sol), pero allí existen 781 establecimientos, parcialmente concentrados en la parte meridional de la Puerta del Sol, entre Carrera de San Jerónimo y Atocha, donde está el otro núcleo fundamental de diversión denominado «barrio de las Letras» o «Huertas». El crecimiento se aceleró a partir de 2010, particularmente en 
Chueca y Malasaña, donde abrieron cerca de doscientos locales; sin embargo, el peso relativo de esa actividad es superior en Sol $(29 \%)$ y Cortes $(40 \%)$. Estos datos, referidos a un territorio mayor que el estudiado, contextualizan lo ocurrido al borde de la Gran Vía, donde inversiones intensivas han dado a la función hostelera mayor continuidad espacial y una estructura más evolucionada. Hasta hace menos de veinte años estaba definida por un elevado número de alojamientos para viajeros y cafeterías, mezcladas con bares de tipo corriente al pasar a calles adyacentes. Hoy las grandes cafeterías prácticamente desaparecieron del eje principal, sustituidas (no necesariamente en los mismos locales) por bares de tapas, fastfoods o cafés pertenecientes a cadenas internacionales. En espacios laterales la supervivencia de las empresas familiares, más vinculadas a los residentes, depende como veremos de la revalorización y el avance de la restauración étnica.

El sector hotelero, relacionado con el turismo y la capitalidad, experimentó durante el último cuarto de siglo un doble proceso de reconversión selectiva y redistribución geográfica. Según la guía oficial de hoteles en 1987 había 224 establecimientos, fuertemente jerarquizados pues casi el $84 \%$ de ellos eran hostales, pensiones o residencias de dos o una estrellas, residuo en muchos casos de formas tradicionales y precarias de alojamiento, parcialmente vinculadas a la prostitución en calles marginales. En 1995 y por efecto del ajuste sólo quedaban 145 empresas, permaneciendo invariable el número de hoteles lujosos o de nivel medio-alto: 36 en 1987; 34 en 1995. Las categorías inferiores disminuyeron un tercio en la Gran Vía, derivando en ocasiones hacia la función de geriátricos informales, o la acogida de excursiones estudiantiles a precio módico por tratarse de locales desvencijados. Pero en las márgenes de la arteria principal más de un $40 \%$ de los hospedajes modestos y para alquiler por horas cerró sus puertas, a causa de la obsolescencia o disfuncionalidad del negocio, la jubilación de sus dueños y la presión que ejercían otras actividades terciarias o un sector inmobiliario interesado en transformar las casas históricas.

En 2015 parece haber culminado la reordenación, con un moderado aumento hasta las 165 empresas. La Gran Vía mantiene su volumen de actividad (41 establecimientos), tras un balance entre cierres y aperturas que trae nuevos hoteles, mientras otros se modernizan o cambian de manos (Vincci, Petit Palace), elevando el estándar promedio. El proceso actual se alimenta con posibles reaperturas, como la del Hotel Plaza (cerrado en 2006) en la plaza de España, a instancias de un promotor chino, o reconversiones de propiedades públicas, caso de la Consejería de Educación de la Comunidad de Madrid, que acogerá un hotel Vincci. Los hostales, menguados, sobreviven rentabilizando espacios interiores de edificios envejecidos, donde llegan a estratificarse hasta siete hospedajes (portales número 15 y 44). En el área de mayor influencia el reparto de las plazas de alojamiento es ahora menos aleatorio que en el pasado, saliendo reforzados los ejes comerciales conducentes a la Puerta del Sol y a las zonas donde avanzan la rehabilitación o la gentrificación, caso de Fuencarral (dieciséis establecimientos) u Hortaleza respecto a Malasaña, el Triángulo Ballesta o Chueca. Los lugares de mayor accesibilidad o cercanía a los recorridos turísticos (Alcalá, San Bernardo, Aduana) ven proliferar, junto a los antiguos hostales, hoteles exclusivos y cadenas como Petit Palace, Best Western y Exe (cinco, tres y dos edificios respectivamente). Se multiplican los negocios regentados por extranjeros, los pequeños hoteles con encanto o los que ofrecen apartamentos, suites o estudios ( $16 \%$ del total) y los destinados a la comunidad homosexual, predominando categorías de tres y dos estrellas. El número de plazas saltó desde las diez mil de 2009 a las doce mil estimadas hoy por los profesionales del sector (CEIM, 2009).

En cuanto a la hostelería de restauración, cafés, cervecerías o bares de copas, representaba, a finales de 2014, al menos la mitad de los locales en 41 calles y dos tercios o más del total en 16. Se trata entonces de una constelación, ausente sólo en las vías más caras y su opuesto, las zonas tranquilas. El desbordamiento desde la Gran Vía logra una soldadura con los focos de concentración previa, tanto Malasaña y Chueca, cuyo germen se sitúa relativamente lejos de ella, como el enclave existente al sur de la plaza de Santo Domingo (Conchas, Veneras, Costanilla de los Ángeles), donde subsiste, en la calle Caños del Peral, un conjunto residual de burdeles cercanos al teatro Real. La densidad de establecimientos y la distribución de sus tipologías dependen de una serie limitada de factores, ante todo la posibilidad de colocar terrazas permanentes, condición que reúnen una veintena de calles y plazas. Eso determina una relación directa con las peatonalizaciones en la parte alta de Preciados (16 establecimientos), Montera o Cuesta de Santo Domingo, donde en poco tiempo se han formado corredores de oferta variada y cierta calidad que hacen pensar en operaciones planificadas. Por otro lado la hostelería vanguardista, de carácter original o imaginativo al adaptar comercios antiguos, reproducir viejas tiendas de alimentación o librerías, suele asomarse a las vías principales (calle Pez) o más raramente secundarias dentro de ámbitos en rehabilitación, donde se combina con el comercio de es- 


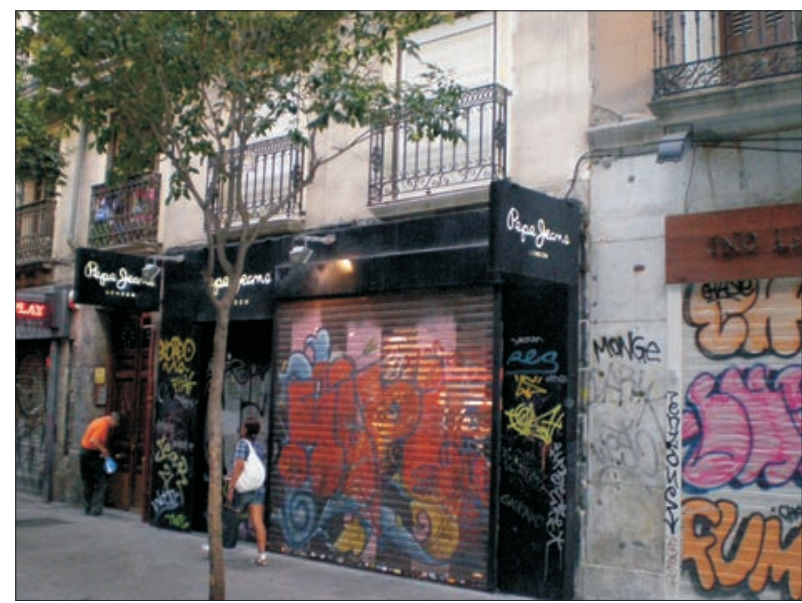

FIG. 7. Resistencias del barrio bohemio al gran capital.

tilo, arte o diseño. Eso ocurre en las calles del Triángulo Ballesta, que suman una cuarentena de locales nuevos, particularmente Corredera Baja de San Pablo y Barco. Al este de Hortaleza, el umbral de Chueca (San Marcos, Libertad, Barbieri) está singularizado por la gastronomía étnica selecta, restauración especializada, bistrós, cafés de tipo antiguo y locales de diseño. Al contacto con la Gran Vía (Infantas y sobre todo Reina) la dotación es más exclusiva (coctelerías, creperías, pintxos vascos), invadiendo el primer tramo del eje principal. En áreas menos caras (barrios de Amaniel, Las Cortes o Santo Domingo la tematización está presidida por el sector de la restauración étnica popular, e intercalaciones recientes de negocios mejores. Teóricamente los perfiles singularizados denotan mayor madurez que las composiciones mixtas, pero a este respecto estamos ante un espacio de fuertes contrastes y gran diversidad a pequeña escala, como denota el carácter absolutamente heterogéneo de algunas bocacalles al eje mayor (Silva, Jacometrezo, Flor Baja).

\section{ENTRE EL DESPOBLAMIENTO Y LA GENTRIFICACIÓN}

Entre el Padrón de 2003 y la actualización correspondiente al 1 de febrero de 2015 el censo ha caído un $16,35 \%$, quedando en 20.126 habitantes. Tradicionalmente estuvo más poblado el margen septentrional, donde se conserva mejor la trama histórica, fragmentada y con ocupación densa, mientras que al sur el tejido aparece en términos generales más alterado, por adaptaciones sucesivas que perpetuaron su centralidad, al agrupar usos no habitacionales. Hoy las quince manzanas de casas com- prendidas entre la calle Montera y la plaza de Santo Domingo apenas rebasan los 1.600 residentes, volumen que del lado opuesto, entre Ballesta y Pizarro, prácticamente se logra con cinco manzanas. El saldo negativo es universal, aunque su cuantía varía localmente según la diferente incidencia del envejecimiento demográfico, la terciarización y la rehabilitación urbana o la gentrificación, que desplazan a los antiguos residentes y extranjeros. El juego de esos factores determina pérdidas generalizadas de intensidad moderada (10-20\%) y procesos más localizados de carácter agudo (20-32\%) al pie de las arterias estructurantes (Fuencarral, Hortaleza, Montera), en sectores populares con residuos de ocio marginal (Caballero de Gracia, Jardines) o ámbitos laterales de carácter mixto (Leganitos, Fomento), absorbidos tardíamente (Fig. 8). La mayor estabilidad corresponde a la parte más noble, donde el primer tramo de Gran Vía se articula con Alcalá y Barquillo, pero fuera de ahí menguan más o menos significativamente los pobladores tradicionales o más recientes de clase baja, sin reemplazo suficiente al menos hasta septiembre de 2014. Después hay un cambio de tendencia en la mitad de las dieciséis secciones censales analizadas, que experimentan ganancias muy leves tanto en Pez-Luna como Amaniel, la parte cercana a Sol o Leganitos, frente al resto donde continúa la caída.

Esa tónica regresiva ha corregido sensiblemente la estructura demográfica, rebajando la participación de los extranjeros en un 8,96\% entre 2003 y 2015, de manera que ya no totalizan ni la cuarta parte del volumen total de población. Los caserones vetustos, las viviendas interiores o precarias de las zonas más depauperadas, alimentaron en años pasados un fenómeno de gueto en el que hallaban alojamiento contingentes abultados de inmigrantes. Llegaron a representar en 2003 más de un tercio, e incluso porcentajes situados entre el $39 \%$ y $46 \%$ del vecindario, en los lugares que más efectivos cederán después con la reconquista inmobiliaria: proximidades de Montera (Caballero de Gracia, Jardines), Malasaña entre San Bernardo, la calle y plaza Luna, además de las espaldas de la Telefónica y Sepu (Barco, Desengaño), sin olvidar Fuencarral, Hortaleza y las inmediaciones de Vázquez de Mella (Chueca). En todos los casos la disminución superó el $20 \%$. La merma del censo alteró la composición por edades en la parte media y baja de la pirámide, pues se contraen los jóvenes $(-1,81 \%)$ en beneficio de los adultos $(+1,49 \%)$ mientras el grupo de los ancianos permanece invariable, sólo que ahora duplica ampliamente al de menor edad. La mayor reducción dentro del segmento entre 0 y 14 años coincide con áreas en reestructuración, de manera que la juventud relativa es 


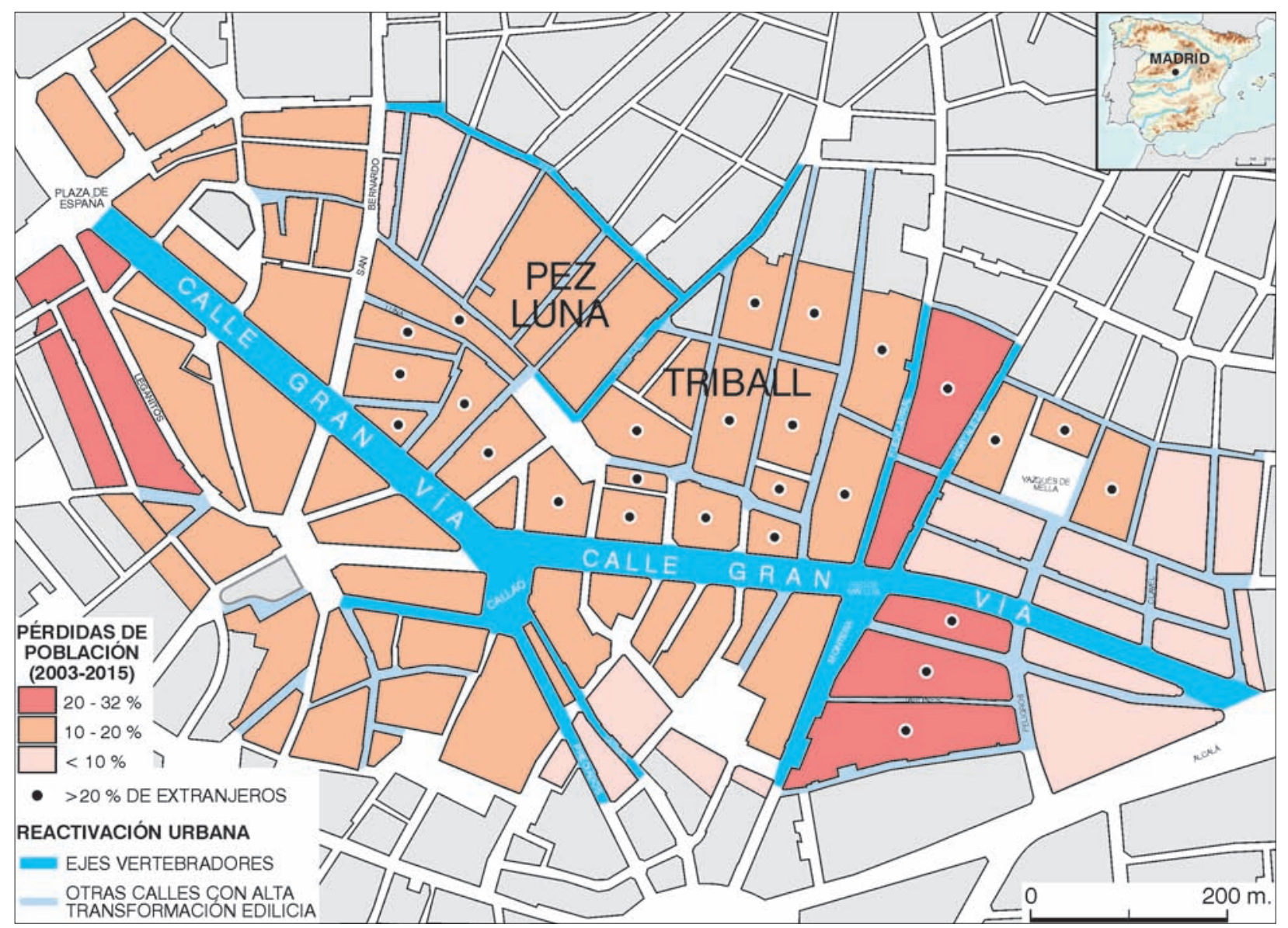

FIG. 8. Correlación entre los procesos económicos, la rehabilitación edificatoria y la variación demográfica.

hoy un atributo relegado a las profundidades de Malasaña, y a escala general el efecto más claro de la sustitución sociodemográfica es por el momento la adición de adultos, comprensible por la débil fecundidad, los modelos familiares o la edad promedio no muy baja de quienes ocupan las nuevas viviendas. Los récords de crecimiento de ese estrato se disponen discontinuamente en los rebordes superior (Amaniel, Pez-Luna, Triball) e inferior (Santo Domingo, triángulo Alcalá-Gran Vía).

Para esta escala de análisis sólo es posible un acercamiento parcial al fenómeno de la gentrificación, con los microdatos del Censo de 1991, el de 2001 y el Padrón de 2014. El punto de partida es la composición socio profesional de 1991, bastante equilibrada ya que las categorías superiores (profesionales, técnicos, directores y gerentes) sólo representaban más de un $30 \%$ del total al sur de la Gran Vía, entre Red de San Luis y plaza de España, pero en ningún caso descendían del $24 \%$. Eso confirma el análisis de Muñoz Carrera (2011, p. 11), que demuestra que el enriquecimiento social entre 1996 y 2001 comenzó precisamente allí. Al contrario, los menos cualificados superaban el $37 \%$ en las calles situadas entre Clavel y Montera, y alcanzaban el 38\%-40\% al cruzar a Chueca y Malasaña. Diez años después el Censo de 2001 corrobora esos focos de rentas bajas, uno entre Fuencarral y Corredera, el otro al este de la calle Montera, pues sólo allí las cinco categorías profesionales inferiores suman más de la mitad del total (54\%), y algo menos (47\%) en los tramos altos de Barco y Valverde. En consecuencia los grupos desfavorecidos se concentraban en los barrios con más viviendas desocupadas, Cortes y Universidad (25\%-30\%), en fecha anterior a la eclosión inmigratoria que tendrá allí particular incidencia: todavía en 2008 las zonas articuladas por las calles Desengaño y Jardines excedían un $40 \%$ de extranjeros.

En cuanto a los últimos años, y a falta de datos desagregados sobre profesiones, la información del Padrón de 2014 acerca del nivel de estudios entre la población 
de 25 o más años sirve para medir relativamente el proceso de aburguesamiento. El arco que va desde los diplomados a los títulos superiores suma ya entre un $49 \%$ y $55 \%$ del total en torno al primer tramo de la Gran Vía y las manzanas situadas detrás del edificio España. Otras ocho secciones censales, incluyendo la orla tanto meridional como septentrional de la Gran Vía al oeste de Red de San Luis y Fuencarral, tienen ya porcentajes superiores al $40 \%$, que también se alcanzan entre San Roque, Corredera y Pez, lo cual certifica el avance de la elitización por Malasaña. El proceso parece más retrasado entre Fuencarral y Hortaleza, en Chueca y entre Clavel-Montera, donde aun así los titulados fluctúan entre $36 \%$ y $39 \%$. Una fracción equivalente (37\%-40\%) carece de estudios o los tiene de bachiller y primer grado de formación profesional, de manera que pervive una cierta dualidad, pues la transformación de edificios, la inflación de los precios y el efecto de la crisis han recortado el número de extranjeros, pero la mala situación económica también parece ralentizar las inversiones inmobiliarias y la llegada de gentries. El resultado es un mosaico donde la regeneración y conquista social avanzan, como un punteado a partir del cual se produce coalescencia, pero no tan rápida ni rotundamente como para borrar la situación de partida (Ardura Urquiaga, 2014, p. 5; García Pérez, 2014, p. 86).

\section{FUENTES}

Ayuntamiento de Madrid: Archivo de Villa, documentos digitalizados, Centenario de la Gran Vía <http://www. madrid.es/portales/munimadrid/es/Inicio/Ayuntamiento/ Cultura-y-Ocio/Cultura/Archivo-de-Villa> (diversas consultas). Sistema de Información Geográfica de Urbanismo, Visualizador Urbanístico: Catálogo y Fichas de elementos Protegidos; Censo de Locales (locales con puerta de calle); Licencias Urbanísticas <http://www-2.munimadrid.es/urbanismo_inter/visualizador> (diversas consultas). Plan General de Ordenación Urbana de Madrid, 1997, Normas Urbanísticas, 442 pp. Plan General de Ordenación Urbana de Madrid, 1997. Compendio de las Normas Urbanísticas, Mayo 2014, 599 pp. Revisión Avance Plan General 2013-2014 <http://www.madrid.es> (diversas consultas). Banco de Datos, Información Estadística, Demografía y Población, Población por Distritos y Secciones Censales: Padrón Municipal de Habitantes, 1 de noviembre de 2003, 1 de julio de 2014, 1 de febrero de 2015, <http:// www-2.munimadrid.es/TSE6/control/mostrarDatos> (diversas consultas). Censos de Población y Viviendas, 2001 y 2011, Padrón Municipal de Habitantes, 22 de julio de 2014, <http://www.madrid.es/portales/munimadrid/es/Inicio/El-Ayuntamiento/Estadistica/Areas-de-informacionestadistica $>$ (diversas consultas).

Comunidad de Madrid, Instituto de Estadística: Censo de Población de 1991; Directorio de Unidades locales de Actividad Económica, datos por distritos y barrios, 1998-2014, <http://www.madrid.org/iestadis/fijas/ estructu> (diversas consultas).

\section{BIBLIOGRAFÍA}

Alaminos López, E. (2009): «La Gran Vía, collage urbano», en Ayuntamiento de Madrid: Gran Vía de Madrid 1910-2010. Centenario, pp. 51-85.

Almarza, C. (2010): «Oculto tras la Gran Vía». MásDeco, 17 de agosto de 2010, <http://www.masdecoracion.latercera.com>. [Consulta: 8-12-2014.]

Ardura Urquiaga, A. (2014): «Madrid. Espacio público confiscado. La privatización y resignificación del espacio público en los procesos de transformación material de las plazas del centro de Madrid». Geocrítica. XIII Coloquio Internacional de Geocrítica: el control del espacio y los espacios de control, $17 \mathrm{pp} .,<\mathrm{www} . \mathrm{ub} . \mathrm{edu} /$ geocrit/coloquio2014>. [Consulta:10-12-2014.]

Asamblea Ciudadana Barrio Universidad (Acibu) (2010): «Vecinos de Centro elaboran un manifiesto contra la degradación de la Gran Vía aprovechando su centenario», <www.europapress.es>. [Consulta: 18-7-2014.]

Ayuntamiento de Madrid (2009): Gran Vía de Madrid, 1910-2010. Centenario, 220 pp., <http://emmoriademadrid.es>. [Consulta: 24-7-2014.]

- (2009a): Memoria de gestión 2008, 12 pp., <www. madrid.es>. [Consulta: 14-6-2014.]

- (2009b): «Plan de Acción para la Revitalización del Centro Urbano», en Revitalización del centro urbano, pp. 211-253.

- (2009c): Plan de calidad del paisaje urbano, 212 pp., $<w w w . m a d r i d . e s>$. [Consulta: 14-12-2014.]

- (2010): «100 años. Gran Vía. Madrid», <http://www. granvia.memoriademadrid.es $>$. [Consulta: 21-7-2014.]

- (2010a): Iniciativas para la revitalización urbana de Madrid. Almendra central, 63 pp.

- (2010b): «Plan de Acción para la Revitalización del Centro Urbano», en Memoria de Gestión 2009, pp. 189-224.

- (2011): «Iniciativas para la revitalización urbana», en Madrid.Revitalización del Centro, 54 pp.

- (2011a): Proyecto Madrid Centro, 6 vols. 
CAM/CEIM (2010): Informe sobre el comercio en Madrid. Situación y propuestas empresariales. $186 \mathrm{pp}$.

CÁmara de Cuentas. Comunidad de Madrid (2006): Informe de fiscalización de la empresa Arrendamientos y Promociones de la Comunidad de Madrid, S. A. (Arproma, S. A.), 60 pp., <http://www.madrid.org>. [Consulta: 27-1-2035.]

Campano, S. (2009): «Los comercios de Triball demuestran que es posible crear negocios de éxito en tiempos de crisis». Cámara de Comercio (25 de febrero de 2009), <www.camaramadrid.es/asp/prensa>. [Consulta: 10-12-2014.]

CAPPA, M. (2014): «Ana Botella impulsa un plan de urbanismo sin la participación ciudadana». La Marea (12 de junio de 2014), <www.lamarea.com>. [Consulta: 4-12-2014.]

CEIM (2009): «Documento de sugerencias que presenta CEIM al resumen ejecutivo del Plan Director de Intervención en el Eje de Gran Vía» (16 de octubre de 2009), 7 pp., <www.ceim.es>. [Consulta: 10-12-2014.]

- (2010): Informe sobre el comercio en Madrid, 186 pp.

«Chueca: descripción urbanística», en Análisis urbanístico de barrios vulnerables. Departamento de Urbanística y Ordenación del Territorio/IJH/Ministerio de Fomento, 2011, 4 pp.

COAM (s. f.): «Edificios significativos de la Gran Vía», 33 pp., <www.coam.org>. [Consulta: 24-7-2014.]

Corral, J. (1980): «La Gran Vía», en P. Navascués Palacio (coord.): Madrid. Instituto de Estudios Madrileños/Espasa-Calpe, Madrid, t. IV, pp. 1.301-1.321.

- (2002): La Gran Vía, historia de una calle. Sílex, Madrid, 218 pp.

De la CRuZ, L. (2010): «La Gran Vía Diagonal: el plan que casi acaba con el barrio», Somos Malasaña, 11 de enero, 1 p., <http://www.somosmalasana.com/>. [Consulta: 10-12-2014.]

«El comercio como motor de renovación del centro de Madrid». Barómetro de Economía de la Ciudad de Madrid, Iv (2008), monográfico, pp. 103-115.

«El sector de la moda en Madrid. Dimensión, características y distribución comercial». Barómetro de Economía de la Ciudad de Madrid, núm. 27 (2011), monográfico 3, pp. 115-141.

Ezquiaga Domínguez, J. M., J. Barros Guerton y G. PERIBÁÑEZ AyAla (2013): «La rehabilitación como sector de futuro en Madrid». Barómetro de Economía de la Ciudad de Madrid, núm. 35 (primer trimestre 2013), pp. 103-142.

Federación de Comerciantes y Vecinos del Centro de MADRID (2013): Informe, 35 pp.
Federación Regional de Asociaciones de Vecinos de MAdRID (FRAVM) (2005): Propuestas estratégicas para el centro histórico de Madrid, 193 pp.

Fernández Ramírez, C., I. GonZÁlez García y N. Morán Alonso (2010): «La singularidad de la Gran Vía en la centralidad madrileña. Procesos de homogeneización y resistencia», en C. Cornejo Nieto, J. Morán Sáez y J. Prada Trigo (coords.): Ciudad, territorio y paisaje. Reflexiones para un debate multidisciplinar. CSIC, Madrid, pp. 36-49.

García Gallo, B. (2011): «Plazas secuestradas a precio de saldo». El País (5 de diciembre de 2011), <http:// www.elpais.com/diario>. [Consulta: 8-12-2014.]

García PÉREz, E. (2014): «Gentrificación en Madrid: de la burbuja a la crisis». Revista de Geografía Norte Grande, núm. 58, pp. 71-91.

Gea Ortigas, M. I. (2010): La Gran Vía, cien años de historia. Ediciones La Librería, Madrid, 222 pp.

Grupo TéCnico de la Mesa de Rehabilitación (2010): Plan Estratégico de Intervención para el Barrio PezLuna, 50 pp.

GuERra GARRIDO, R. (2009): «Los cien años y nombres de la Gran Vía», en Ayuntamiento de Madrid: Gran Vía de Madrid, 1910-2010. Centenario, pp. 15-51.

Gutiérrez, V. (2006): «Un Centro con menos oficinas y más vivienda habitada». El País (8 de enero de 2006), $<$ http://elpais.com/diario/2006/01/08/madrid>. [Consulta: 22-11-2014.]

Hidalgo Monteagudo, R., R. Ramos Garrido y F. Revilla GonzÁlez (1996): El Madrid de la Gran Vía. Ediciones La Librería, Madrid, 140 pp.

InPROTUR (1987): Guía oficial de hoteles. Secretaría General de Turismo, $630 \mathrm{pp}$.

Justo Moreno, A. (2011): «Transformaciones en el barrio de Malasaña. Hacia la gentrificación». Viento Sur, núm. 116, pp. 73-79.

«Madrid avanza el nuevo Plan General de Ordenación Urbana», en Madrid EMT, s. p., <http://www.madridmovilidad .es/es/noticias/año-2013-es>, 2013. [Consulta: 20-11-2014.]

Ministerio de Comercio y Turismo (1995): Guía de hoteles oficial, $1048 \mathrm{pp}$.

Monumenta Madrid (2010): «Edificios históricos. Gran Vía», <www.monumentamadrid.es/AM_Edificios4>. [Consulta: 2-57-2014.]

Muñoz CARrera, O. (2011): «Gentrificación y reestructuración del espacio social en Madrid». Observatorio Metropolitano, 31 pp. (25 de marzo de 2011), $<$ www.observatoriometropolitano.org $>$ [Consulta: 132-2015.] 
Ortín RAMÓN, A. (2012): «Carlyle fracasa en su incursión en el sector inmobiliario español». Cinco Días (11-042012), <http://www.cincodias.com> [Consulta: 22-12015.]

«Plano comercial de la Gran Vía», <http://www.granvia. esmadrid.com $>$. [Consulta: 27-7-2015.]

Pérez, A. (2010): «Foro Cívico Gran Vía: Triball ha lavado la imagen de la zona de Ballesta». Somos Malasaña (9 de mayo de 2010), <http://www.somosmalasana.com>. [Consulta: 15-12-2014.]

Quirós LinARES, F. (1983): «La construcción del centro urbano: política y especulación en la reforma de la Puerta del Sol (1853-1862)». Ería. Revista Cuatrimestral de Geografía, núm. 4, pp. 81-91.

REDACCión (2004): «Entrevista. Sigfrido Herráez, concejal de Vivienda del Ayuntamiento de Madrid y presidente de la EMV». Directiva Construcción, núm. 170, pp. 16-27.

Roca RuIz (2014): «El inmueble estrella de Carlyle en Madrid, en venta». Cinco Días (8 de mayo de 2014), $<$ http://www.clipmedia.net $>$. [Consulta: 3-1-2015.]

Roces, M. (2004): «Áreas y zonas de rehabilitación; experiencias de la asociaciones de vecinos de Madrid en 2004. Ponencia presentada a las Jornadas Estatales sobre Vivienda Social celebradas en Valencia en 19, 20 y 21 de noviembre de 2004», 21 pp., <http://www. aavvmadrid/org >. [Consulta: 3-1- 2015.]

Ruiz Chasco, S. (2014): «Videovigilancia en el centro de Madrid: ¿hacia el panóptico electrónico?». Teknocultura. Revista de Cultura Digital y Movimientos Sociales, núm. 11 (2), pp. 301-327, <http://teknocultura. net>. [Consulta: 3-12-2014.]
Sanabria Brassart, C., P. Torre Binimelis y S. Gumiel NADADOR (2006): «Procesos recientes de terciarización en la ciudad de Madrid», en VIII Coloquio y Jornadas de Campo de Geografía Urbana. AGE, pp. 555-569.

SAnz López, J. (2011): La Gran Vía de Madrid. Valor actual de expropiación. Sociedad de Tasación, Independencia y Responsabilidad, 11 pp., <www.stvalora. com/ext/pdf/folleto_gran_via.pdf $>$. [Consulta: 19-72014.]

TODO POR LA PRAXIS (2011): «Proceso de gentrificación en el barrio Universidad a causa del proyecto Triball», 8 pp., <http://www.todoporlapraxis.es>. [Consulta: 3008-2014.]

- (2013): «Abandono, especulación, expulsión: gentrificaión. El caso Triball en números», s. p. (26 de diciembre de 2013), <http://www.todoporlapraxis.es>. [Consulta: 25-07-2014.]

«Triángulo de Ballesta». Conocer Madrid (30 de octubre de 2013), <http://conocemadrid.blogspot.com>. [Consulta: 10-12-2014.]

VozPópuli (2013): «Para Madrid 2020, Botella vende la Gran Vía: cada vez más deteriorada y sin comercio tradicional» (17 de agosto de 2013), <http://www.vozpopuli.com>. [Consulta: 19-7-2014.]

Zorrilla Jurado, J. J., y A. Martínez García (2010): La Gran Vía de Madrid, cien años de historia. Alymar, Madrid, $280 \mathrm{pp}$.

Zozaya, M., C. Barrera y J. M. Medrano, (2002): La Gran Vía, escenario de un Madrid cosmopolita, Real Academia de Bellas Artes de San Fernando, Madrid, $74 \mathrm{pp}$. 